\title{
Caught in vicious circles: a perspective on dynamic feed-forward loops driving oxidative stress in schizophrenia
}

\author{
Michel Cuenod ${ }^{1,4}$, Pascal Steullet ${ }^{1,4}$, Jan-Harry Cabungcal ${ }^{1}$, Daniella Dwir ${ }^{1}$, Ines Khadimallah (D) ${ }^{1}$, Paul Klauser (D) ${ }^{1,2}$, Philippe Conus ${ }^{3}$ and \\ Kim Q. Do iD ${ }^{1 凶}$
}

(c) The Author(s) 2021

\begin{abstract}
A growing body of evidence has emerged demonstrating a pathological link between oxidative stress and schizophrenia. This evidence identifies oxidative stress as a convergence point or "central hub" for schizophrenia genetic and environmental risk factors. Here we review the existing experimental and translational research pinpointing the complex dynamics of oxidative stress mechanisms and their modulation in relation to schizophrenia pathophysiology. We focus on evidence supporting the crucial role of either redox dysregulation, N-methyl-D-aspartate receptor hypofunction, neuroinflammation or mitochondria bioenergetics dysfunction, initiating "vicious circles" centered on oxidative stress during neurodevelopment. These processes would amplify one another in positive feed-forward loops, leading to persistent impairments of the maturation and function of local parvalbumin-GABAergic neurons microcircuits and myelinated fibers of long-range macrocircuitry. This is at the basis of neural circuit synchronization impairments and cognitive, emotional, social and sensory deficits characteristic of schizophrenia. Potential therapeutic approaches that aim at breaking these different vicious circles represent promising strategies for timely and safe interventions. In order to improve early detection and increase the signal-to-noise ratio for adjunctive trials of antioxidant, anti-inflammatory and NMDAR modulator drugs, a reverse translation of validated circuitry approach is needed. The above presented processes allow to identify mechanism based biomarkers guiding stratification of homogenous patients groups and target engagement required for successful clinical trials, paving the way towards precision medicine in psychiatry.
\end{abstract}

Molecular Psychiatry (2022) 27:1886-1897; https://doi.org/10.1038/s41380-021-01374-w

Schizophrenia research faces many challenges due to the disease complexity and heterogeneity at various levels, from genetic, pathophysiology to clinical phenomenology and stages. Early detection and intervention [1] requires mechanism-based reliable biomarkers that capture circuitry dysfunction, allowing better patient stratification, disease progression monitoring and treatment. To this goal, it is essential that experimental research on animal models is coupled with translational clinical observations [2]. This review reports attempts to uncover mechanisms underlying schizophrenia pathophysiology at molecular, circuitry, system and cognitive levels, and identify novel preventive and therapeutic measures.

A longstanding pathophysiological approach to schizophrenia emphasizes the role of abnormal neurodevelopment in relation to long-term alterations of neural circuits that lead to the emergence of disease symptoms [3, 4]. Prominent theories associated with the pathogenesis of schizophrenia include dopamine, glutamate/ NMDA [5, 6], neuroimmune/neuroinflammatory [7], mitochondrial hypotheses [8], and excessive microglia-mediated synaptic pruning $[9,10]$, while deficits in gamma-aminobutyric acid (GABA) system and myelination are well documented [11, 12]. Oxidative stress
(OxS) has emerged as a "central hub" in schizophrenia pathophysiology given the converging evidence from environmental and genetic studies. They link this physiological process to cardinal pathological features of the disease including alterations in both parvalbumin-expressing GABAergic neurons (PV neurons) (microcircuits) and myelinated macrocircuits $[13,14]$.

Here, we propose the hypothesis that a dysfunction during development in either NMDAR-mediated signaling, neuroimmune regulation, mitochondria function could initiate "vicious circles" centered on redox dysregulation/OxS, leading to persistent anomalies of PV neurons and oligodendrocytes and ultimately to neural synchronization, cognitive, emotional, social and sensory deficits characteristic of schizophrenia (Fig. 1). The concept of OxS-driven PV neuron impairment is supported by our recent study assessing prefrontal $\mathrm{PV}$ interneurons in a range of animal models carrying genetic and/or environmental risk factors of schizophrenia affecting glutamatergic, dopaminergic, immune and redox signaling [15]. The present paper expands this by reviewing the experimental and clinical evidence pinpointing the complex dynamics of OxS mechanisms and their modulation in relation to schizophrenia pathophysiology.

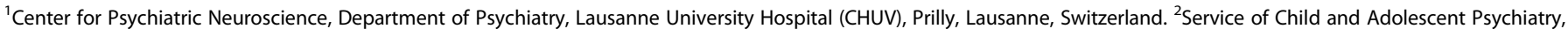

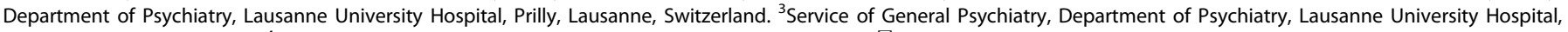
Prilly, Lausanne, Switzerland. ${ }^{4}$ These authors contributed equally: Michel Cuenod, Pascal Steullet. ${ }^{凶}$ email: Kim.Do@chuv.ch
} 


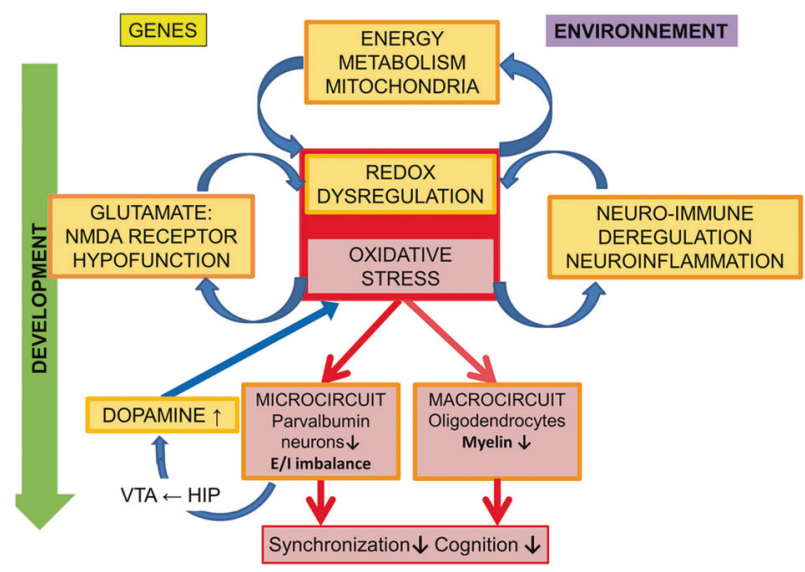

Fig. 1 Schematic representation of the concept proposed in this paper, showing the reciprocal interaction between mitochondria, NMDAR, neuro-immune system, dopamine on one hand and the complex redox regulation/oxidative stress (OxS) on the other. Irrespectively of which is the primary affected system via genetic or environmental factors, this will trigger during development subsequent vicious circles of OxS that can feed on one another and drive durably parvalbumin (PV) neurons and myelin impairments that culminate in the neural synchronization and cognitive deficits characteristic of schizophrenia.

\section{INTERACTIONS BETWEEN REDOX DYSREGULATION AND OXIDATIVE STRESS}

The redox balance between reactive oxygen species (ROS) and antioxidant systems is critical in the brain, which displays a high oxidative metabolism, as compared to other organs. Maintenance of redox homeostasis typically involves the delicate regulation of ROS by redox systems, with evidence that the glutathione (GSH/GSSG), thioredoxin and cysteine/cystine redox systems are differentially modulated under dynamic and non-equilibrium redox conditions [16]. These systems control redox signaling (i.e.Nrf2 redox-signaling pathway) and redox-sensing within cells. Notably, redox-sensing cysteine residues (i.e., thiol switches) provide an orthogonal control system to modulate activity of cellular and physiological mechanisms [17]. Severe and chronic unbalance between ROS and antioxidant systems would lead to oxidative damage on proteins, lipids and DNA with drastic irreversible effects. However, a slight redox dysregulation would lead to reversible oxidation of the thiol switch on redox-sensitive proteins, leading to their functional modifications. This can alter receptor-(NMDAR) and kinase-mediated signaling (Fyn kinase), metalloprotease (MMP9) activity, thus affecting neurotransmission, and cellular proliferation, differentiation, maturation in case of transient redox dysregulation during development [18]. Below, we will focus on the critical role of GSH, without discarding that OXS could also result from dysregulation of other antioxidant systems (thioredoxin [19], peroxiredoxin, sulforedoxin [20]).

Since our first observations on alterations of GSH metabolism in cerebrospinal fluid of schizophrenic patients in the nineties $[21,22]$, evidence that redox dysregulation plays a major role in psychosis has gained prominence. Data accumulated over the last decades point to increased OxS (increased lipid and protein oxidation) and alterations in antioxidant defence systems (vitamin C and E, catalase and superoxide dismutase) in blood, plasma cerebrospinal fluid and post-mortem samples of schizophrenia patients $[18,23-27]$. Various genes directly involved in antioxidant systems have been associated with risk for schizophrenia. They include the catalytic (GCLC) [28] and modulatory (GCLM) [29] subunits of glutamate-cysteine ligase (rate-limiting synthesizing enzyme of GSH), glutathione-S-transferase [30, 31], superoxide dismutase-1 [32], nitric oxide synthase [33, 34].
Genetic variations within some of these genes exert strong functional effects on phenotypes. Thus, carriers of the high-risk GCLC genotype (GAG trinucleotide repeat polymorphism) exhibit lower GSH levels in fibroblasts when challenged with OxS [28], and lower prefrontal GSH levels compared with GCLC low-risk genotypes [13, 28, 35, 36]. Additional research has revealed epigenetic alterations in GSH genes in at-risk individuals who later converted to psychosis [37].

Using in-vivo magnetic resonance spectroscopy, we first reported decreased GSH levels in prefrontal cortex (PFC) of drug naive patients [22]. In line with these findings, recent work has revealed lower levels of GSH in anterior cingulate cortex and thalamus of schizophrenia patients [38, 39]. Although some studies with small numbers of subjects did not observe such decrease $[40,41]$, recent meta-analyses support a GSH deficit in anterior cingulate cortex $[42,43]$. Interestingly, in early psychosis patients, low prefrontal GSH levels were associated with high-risk GCLC genotypes, highlighting GCLC polymorphisms should be considered in pathology studies of cerebral GSH [36]. In first episode psychosis, higher GSH prefrontal levels were associated with favorable prognosis [44]. Reduced levels of GSH in postmortem brains of schizophrenia patients have also been reported [45-47]. In this context, several groups have assessed peripheral blood GSH levels as a window to understand what occurs in the brain $[36,48]$, although it remains unclear whether the reported changes in peripheral GSH levels are a reflection of the brain ones (see also caveats of plasma GSH levels analysis in [18] supplement). Recently, we have demonstrated a negative correlation between high GSH peroxidase (GPx) activity in red blood cells and low brain GSH levels in male early psychosis patients [36]. As such, blood GPx activity may reflect central oxidative status, although these findings require validation in larger cohorts.

\section{VULNERABILITY OF PV NEURONS TO REDOX DYSREGULATION PV neurons in schizophrenia}

One of the most consistent pathological findings in schizophrenia are anomalies in PV neurons and their associated extracellular matrix, the perineuronal net (PNN) [49]. Primarily reported in PV interneurons of the hippocampus (reduced number of PV-immunoreactive neurons) [50,51] and dorsolateral PFC (i.e. abnormal PNN, decreased PV and GAD67 expression) [52], anomalies have been also observed in other cortical and subcortical regions [53-58], and cerebellum [59]. Abnormal function of these diverse PV neurons affects high-frequency (gamma) neuronal synchronization within brain regions and cortico-thalamic network dynamic [60, 61], impacting sensory processing, attention, working memory, learning, social behavior, fear processing, motor coordination and learning, and contributing to hyperdopaminergia related to positive symptoms [62-69]. As estrogen interacts extensively with PV neurons [70], the drop in this hormone at menopause could also possibly contribute via altered function of these neurons to the increased incidence of late-onset schizophrenia in women. Thus, PV neuron dysfunction appears to be a core of schizophrenia pathophysiology. All these PV neurons are GABAergic inhibitory neurons that can generate action potentials at very high frequency. Therefore, they require considerable energy to sustain intense neuronal activity as during high-frequency synchronization. In this perspective, hemodynamic signals correlate positively with high gamma oscillations [71]. Optimal functional performance of mitochondria [72] is essential to support such strong demand for adenosine triphosphate (ATP) produced by oxidative phosphorylation [73]. This metabolic process can generate ROS through electron leak, thus making PV neurons particularly vulnerable to redox imbalance. One cannot exclude that other micro-circuit-related GABAergic neurons, including the somatostatin ones [74] as well as pyramidal cells [75] could be directly or indirectly affected. 


\section{Preclinical evidence}

Cumulating evidence indicates that PV neurons are indeed vulnerable to redox dysregulation-stemming from a compromised antioxidant system or ROS overproduction. Although most preclinical studies have focused on hippocampal and prefrontal PV interneurons, PV neurons are also affected by redox dysregulation in other regions, including thalamus reticular nucleus [56, 76], amygdala [77], globus pallidus [77], inferior colliculus [78]. Overall, PV neurons are impacted when antioxidant systems (e.g., GSH, selenoprotein $\mathrm{P}$, catalase, superoxide dismutase) are compromised [78-80]. In a transgenic mouse expressing low GSH levels (Gclm $\mathrm{KO}$ ), we found reduced number of prefrontal and hippocampal PVimmunoreactive interneurons together with diminished highfrequency neuronal synchronization [81, 82], reduced number of PV-immunoreactive neurons in thalamus reticular nucleus together with altered firing properties [56], thus demonstrating the functional consequence of a redox dysregulation. In Gclm KO mice and other models involving a weakened antioxidant capacity, the OxS is more prominent in PV neurons as compared to other types of GABAergic or principal neurons [78-80]. Notably, OxS precedes PV neuron deficits [82] and is accompanied by a weakening of the PNN enwrapping them [77, 81, 82]. These alterations are reversed by the antioxidant $\mathrm{N}$-acetyl-cysteine (NAC), confirming the causal role of OxS. Other works found that superoxide overproduction by NADPH oxidase (NOX) has deleterious effects on PV neurons, with evidence that NOX inhibition prevents PV neuron impairment induced by either NMDAR antagonist [76] or social isolation [83].

Remarkably, we further showed that PV neuron deficit in anterior cingulate cortex is associated with OxS in a variety of animal models carrying genetic and/or environmental risks relevant to diverse etiological aspects of schizophrenia [15]. Specifically, OxS correlates negatively with the integrity of PV neurons and their PNN [15]. Overall redox dysregulation/OxS appear as a common pathological mechanism leading to PV neuron-associated network anomalies in schizophrenia (Fig.1).

\section{Developmental perspective}

PV neurons are more susceptible to a redox dysregulation resulting in OxS during postnatal development rather than later in life [81, 84]. Indeed, a transient GSH deficit induced by L-buthionine-(S,R)-sulfoximine during early postnatal life causes long-term reduction of PV neuron density in anterior cingulate cortex [85-87]. Likewise, a permanent reduction of PV neuron density in anterior cingulate cortex of $\mathrm{Gclm}$ KO mice occurs following the administration of GBR-12909 (dopamine re-uptake inhibitor leading to excess extracellular dopamine level that generates ROS through its catabolism) during postnatal development, but not adulthood [81]. The vulnerability of immature PV neurons has been associated with the absence of yet fully mature PNN [81]. Indeed, PNN plays a key role in protecting PV neurons from OxS [81], but also in promoting their maturation. The maturation and integrity of PV neurons require incorporation of the non-cell autonomous homeobox protein Otx2 via its binding to the PNN $[88,89]$. Thus, PV neurons during early postnatal development are less protected from OxS that also disrupts PNN formation, leading to long-term impairment of PV maturation and stabilization of synapses within their networks. The OxS-induced degradation of aggrecan-enriched PNN is mediated by metalloproteinases, including MMP9 [90, 91]. Of note, the mRNA expression pattern in PV neurons of schizophrenia patients indicate an immature state [92], including altered expression of genes regulating cell cycle and apoptosis [93]. Reduced expression of $\mathrm{PV}$ appears mediated in part by epigenetic mechanisms [94, 95].

The implication of redox dysregulation/OxS in the abnormal development of PV neurons has been further corroborated in neurodevelopmental animal models of schizophrenia that do not involve direct manipulation of the redox system. Adult rats with a neonatal ventral hippocampal lesion display OxS, reduced number of PV-immunoreactive interneurons, and weakened PNN in medial PFC which could be prevented through juvenile and adolescence treatment with NAC, or ebselen [84]. Likewise, early postnatal injection of ketamine leads in adulthood to OxS and decreased number of prefrontal PV-immunoreactive interneurons that is precluded by adolescent NAC treatment [80]. Finally, adult rats that have received the mitotoxin Methylazoxymethanol Acetate (MAM) during late gestation show deficits in hippocampal and prefrontal PV neurons, weakened PNN, and impaired neuronal synchronization alongside with OxS and decreased brain GSH levels $[15,96-98]$. Moreover, OxS induced by a prenatal stress slows down the migration of inhibitory interneuron progenitors, a migration that can be accelerated by antioxidants [99]. Altogether, these indicate that OxS during development disrupts maturation and function of PV neuron-associated networks.

\section{Critical period of plasticity}

Given that aperture and closure of the critical period of plasticity involves PV neuron maturation in conjunction with PNN and myelin formation-all of which are sensitive to disturbances in redox homeostasis - a redox dysregulation may disrupt critical periods during neurodevelopment. Thus, the neocortex of mice remains plastic beyond its typical critical period when redox dysregulation is restricted to PV neurons [100]. We therefore speculate that PV neuron-specific regulation of redox state may play a role in balancing plasticity and stability of cortical networks during development, relevant to distractibility, basic symptoms and disorders of the self-perception known to be central to the phenomenology of schizophrenia. Furthermore, the vulnerability to stresses is linked to the critical period [101] which is characterized by immature and not yet fully formed PNN unable to protect PV neurons from OxS-induced damage [81]. That is, mistimed developmental trajectories of brain plasticity stemming from redox dysregulation may confer susceptibility to environmental stresses and risk for neurodevelopmental disorders such as schizophrenia [102].

\section{RECIPROCAL INTERACTIONS BETWEEN MITOCHONDRIAL DYSFUNCTION AND REDOX DYSREGULATION/OXIDATIVE STRESS}

Cumulating evidence exists linking mitochondrial dysfunction and oxidative phosphorylation generating ROS to schizophrenia [103-109]. In-vivo ${ }^{31}$ P-magnetic resonance spectroscopy revealed direct and compelling evidence for brain bioenergetics abnormality in schizophrenia patients [110]. This includes altered expression of mitochondria-related genes in prefrontal layer-IIIPV neurons [111] and of the oxidative phosphorylation pathway resulting in OxS in interneurons derived from induced pluripotent stem cells [112]. Acute metabolic stress induced by environmental factors (infection and psychosocial stress) known to be associated with schizophrenia can trigger pervasive OxS in neurons [113], leading to mitochondrial dysfunction, which in turn, generates more ROS and neuronal damage. PV neurons have high mitochondrial content, due to the energy demand required to sustain their fast-spiking characteristics. This renders them particularly susceptible to OxS and mitochondrial damage [114].

\section{Preclinical evidence}

Mice with a deletion of the 22q11.2 locus containing most proteins expressed in mitochondria [19] show increased cytoplasmic 8-oxo-2'-deoxyguanosine (suggesting mitochondrial DNA oxidation), reduced number of $\mathrm{PV}$-immunoreactive interneurons, and weakened PNN in anterior cingulate cortex [15]. High 8-oxo2 '-deoxyguanosine alongside with PV neuron defects is a common pathological feature in many animal models relevant to 
schizophrenia [15]. Following the blockade of NMDARs during early postnatal life, mitochondria in prefrontal PV interneurons show reduced membrane potential and contain high ROS levels [80]. Moreover, mitochondria can act in concert with parvalbumin through homeostatic mechanisms to regulate $\mathrm{Ca}^{2+}$ signaling, buffering and sequestration. Thus, parvalbumin modulates mitochondrial volume and dynamics by altering fusion, fission and mitophagy [115]. In PFC of Gclm KO mice, we identified a novel molecular mechanism linking mitochondria and OxS-induced PV neuron impairments. OxS induces upregulation of the microRNA miR-137 in PV neurons, leading to decreased COX6A2, a subunit of cytochrome c oxidase complex IV specific to PV neurons, and to impaired mitophagy with accumulation of damaged mitochondria [116]. Remarkably, the mitochondria-targeted antioxidant, mitoquinone mesylate (MitoQ), rescues this entire pathological process.

\section{Clinical evidence}

Similar alterations of miR-137, COX6A2, and mitophagy markers were identified in plasma of early psychosis patients. Exosomal miR-137 were increased, while COX6A2 and mitophagy markers decreased. Moreover, higher exosomal miR-137 and lower COX6A2 levels were associated with weaker EEG $40-\mathrm{Hz}$ auditory steady-state response. As auditory steady-state response requires proper PV neuron-related networks [116], these suggest that alterations of combined miR-137/COX6A2 plasmatic exosomal levels represent a proxy marker of impairments of cortical PV neuron microcircuits. These findings allowed to stratify early psychosis patients in two subgroups: (a) patients "with mitochondrial dysfunction" characterized by exosomal high miR-137 and low COX6A2, presumably representing PV neuron dysfunction associated with mitochondria and (b) patients "without mitochondrial dysfunction" having miR-137 and COX6A2 levels within the healthy control range. Compared to patients "without mitochondrial dysfunction", those "with mitochondrial dysfunction" exhibit impaired auditory steady-state response, worse psychopathological status, neuro-cognitive performance and global and social functioning. In this context, it should be noted the robust genetic association between miR-137 polymorphisms and schizophrenia in large-scale GWAS studies [117].

Altogether, these results suggest that exosome-based miR-137 and COX6A2 levels are biomarkers of a PV neuron energy metabolism deficit and gamma oscillation alterations leading to an excitatory/inhibitory imbalance related to various schizophrenia symptoms and functional outcome. This study paves the way for biomarker-guided treatment targeting mitochondrial impairments in a specific subgroup of patients. It also allows monitoring the effect of an intervention relying on both peripheral and central markers. Thus, future stratified clinical trials with mitochondriatargeted antioxidants are warranted. These novel findings highlight a compromised mitochondrial function in PV neurons of schizophrenia patients that may critically act in a feed-forward regulatory loop contributing to their OxS-driven deficits (Fig. 1).

\section{RECIPROCAL INTERACTIONS BETWEEN NMDA-RECEPTOR (NMDAR) HYPOFUNCTION AND REDOX DYSREGULATION/ OXIDATIVE STRESS}

Compelling evidence supports the hypothesis of a hypofunction of NMDARs as one mechanism contributing to psychosis and schizophrenia pathology $[6,118,119]$. Genetic risk factors related to NMDARs or associated proteins $[20,120,121]$ suggest that hypofunction of NMDARs and mediated signaling pathways could disrupt normal brain maturation, thus contributing to the emergence of schizophrenia. The pathological mechanisms associated with NMDAR dysfunction during early postnatal development have been unveiled by series of preclinical studies pointing to the involvement of OxS [20]. Transient blockade of NMDARs by antagonists during early postnatal life causes at adulthood behavioral phenotypes relevant to schizophrenia [122-124]. Such perinatal functional disruption of NMDARs causes a persistent oxidative state of GSH and prominent OxS in prefrontal PV neurons [80]. This has a long-term impact on PV neurons [125, 126]. But, NAC alleviates both behavioral anomalies [123] and PV neuron impairments [80]. Notably, mice lacking the NADH-oxidase-2, an enzyme that produces superoxide, are resilient to perinatal ketamine-induced PV neurons defects [126]. A genetic model of NMDAR hypofunction relevant to schizophrenia, the D-serine racemase $\mathrm{KO}$ mouse which show altered neuronal oscillations [127], also have reduced number of prefrontal PV interneurons together with OxS [15], both of which can be prevented by an early-life NAC treatment (coll. with Joe Coyle, unpublished). Collectively, these indicate that a disruption of NMDAR function during postnatal development affects normal maturation of PV neurons via mechanisms related to OxS [20, 126]. Cortical PV interneurons undergo an early postnatal and activity-dependent switch of the GluN2 subunit composition of NMDARs, with GluN2A becoming more numerous than GluN2B subunits during the time of maturation of these neurons $[128,129]$. We have shown that a genetic deletion of GluN2A delays the maturation of prefrontal PV interneurons and PNN, but also reduces the expression of genes coding for enzymes related to GSH and peroxiredoxin systems [130]. Thus, functional deletion of GluN2A renders PV interneurons susceptible to an oxidative insult during their critical period of maturation leading to long-lasting PV neuron/PNN anomalies and reduced high-frequency neuronal synchrony that are prevented by NAC [130]. Likewise, a specific deletion of the obligatory GluN1 subunit of NMDARs in forebrain interneurons, mostly composed of PV interneurons, leads to increased OxS in PV neurons following social isolation. This is associated with reduced expression of genes involved in several antioxidant systems [131]. Indeed, synaptic NMDAR activity boosts intrinsic antioxidant defenses via transcriptional control of thioredoxin/peroxiredoxin [132] and GSH systems, and enhances the synthesis, recycling and utilization of GSH [133]. This suggests that neurons use NMDAR-mediated signaling to adjust the strength of antioxidant defenses accordingly to their activity and metabolic demand, a phenomenon particularly vital for fast-spiking PV neurons. Noteworthy, deletion of GluN1 also causes reduced expression of the transcriptional coactivator PGC1alpha, which is highly expressed in PV interneurons and is a positive regulator of the expression of genes implicated in mitochondrial function and antioxidant defence [131].

On the other side, oxidative conditions negatively and reversibly modulate NMDAR activity via extracellular redox-sensitive sites located on GluN1-GuN2A receptors $[134,135]$ and inhibition of CaMKII activity [136]. Notably, GSH deficiency induces NMDAR hypofunction and long-term potentiation impairment [137]. Overall, the reciprocal interactions between NMDAR hypofunction and redox dysregulation/OxS can perpetuate vicious feed-forward mechanisms particularly deleterious for the maturation and function of PV neurons (Fig. 1).

\section{RECIPROCAL INTERACTIONS BETWEEN NEURO- INFLAMMATION AND REDOX DYSREGULATION/OXIDATIVE STRESS}

OxS and inflammation are reciprocally interconnected [138] and can activate each other. Increased inflammation was reported both in brain and blood of schizophrenia patients [139, 140], originated by complex interaction between genetic $[9,117]$ and environmental risk factors such as perinatal infections [141] and childhood trauma [142], triggering the release of proinflammatory cytokines that in turn promote free radical production. In Gclm KO mice, we have identified a vicious feed-forward process between OxS and neuro-inflammation occurring early during brain development, which underlies the long-lasting effect 
on PV neuron/PNN integrity [90]. This pathological mechanism involves the following sequential steps: 1 ) activation of the redoxsensitive metalloproteinase-9 (MMP9) by a redox dysregulation; 2) shedding of the receptor for advanced glycation end-products (RAGE) into a soluble part and an intracellular domain which translocates to the nucleus; 3 ) activation of the nuclear factor-kB; and 4) secretion of pro-inflammatory cytokines leading to microglia activation and further ROS production which in turn perpetuates OxS-mediated processes from the juvenile stage to adulthood. Blockade of MMP9 activation during the PV neuron maturation period (early peripuberty) prevents RAGE shedding, microglia activation and OxS, and allows normal maturation of PNN and PV neurons. Translation of these findings to early psychosis patients revealed elevated soluble RAGE (sRAGE) in the plasma of patients compared to healthy controls [90], an effect reversed by NAC [143]. In early psychosis patients with high-risk GCLC genotypes, this increased level of circulating sRAGE was associated with low GABA levels in PFC, potentially implying a central inhibitory/excitatory imbalance linked to shedding of RAGE and highlighting the importance of the genetic vulnerability to redox dysregulation [90]. These new findings set a precedent for mechanistic biomarkers needed for early intervention in psychosis and suggest that MMP9/RAGE pathway modulation may also lead to promising drug targets. Summing up, these results support the concept of reciprocal vicious feed-forward interaction processes between microglia activation and OxS leading to PV neuron impairments (Fig. 1).

\section{OXIDATIVE STRESS, DOPAMINE DYSREGULATION AND PV NEURON IMPAIRMENT IN THE VENTRAL HIPPOCAMPUS}

Research using ${ }^{18} \mathrm{~F}$-dopa Positron Emission Tomography (PET) indicates that clinical high-risk subjects who convert to psychosis show elevated presynaptic dopamine function in the striatum [144] at baseline, and a progressive increase in striatal dopamine function as they transition [145]. This increased dopaminergic neurotransmission would result in un-sequestered dopamine that can be neurotoxic through its metabolism to form ROS such as hydrogen peroxide and quinones [146, 147]. The ensuing OxS has been implicated in damage to neuronal processes in vitro [148], consistent with the reduction of dendritic spines observed in schizophrenia [149, 150].

Preclinical studies (in MAM rat model or via selective manipulation of PV neurons) have highlighted that PV neuron impairment in ventral hippocampus/subiculum or thalamus reticular nucleus result in overactive ventral-subiculum leading to an increased number of active dopaminergic neurons in the ventral-tegmental-area, which in turn drive elevated dopamine neurotransmission in the mesolimbic system [67, 151-153] (Fig. 1). Indeed, as evidenced by the pioneer works of Grace and collaborators, an increased ventral hippocampal activity causes the nucleus accumbens to strongly inhibit the ventral pallidum, which in turn increases the number of spontaneously active ventral-tegmental-area dopamine neurons [151, 154]. Interestingly in MAM rats, OxS-induced impairments of PV neurons in thalamus reticular nucleus [56] lead to the disinhibition of the multisynaptic excitatory pathway "infralimbic-cortex/reuniens/ventral-subiculum", contributing to the ventral-subiculum hyperactivity and the consequent dopamine hyperactivity [153]. NAC treatment prevented the PV deficits in thalamus reticular nucleus and dopamine dysfunction, suggesting that early antioxidant treatment might contribute to dopamine normalization in schizophrenia.

\section{MACROCIRCUIT DYSFUNCTION AND REDOX DYSREGULATION IN RELATION TO DISRUPTED MYELINATION AND WHITE MATTER INTEGRITY DIFFUSION PROPERTIES}

In addition to PV neurons, oligodendrocytes are highly sensitive to altered redox state [155]. Brain diffusion MRI studies show spatially widespread white-matter (WM) abnormalities [156, 157] whose severity increases as the disease progresses [158]. However, from a topological point of view, WM alterations tend to concentrate within fibers interconnecting hub regions and comprising the rich club [159]. The rich club is an organizational property of the brain network that results from a propensity of central brain regions or "hubs" to be more likely interconnected among each other than expected by chance, providing faster routes of transfer and efficient integration of information between remote and separated brain regions [160]. Interestingly, these hub regions which process large amounts of information have high metabolic requirements, are characterized by the co-expression of genes regulating oxidative metabolism, and might be particularly sensitive to OxS [161]. WM abnormalities typically result from dystrophic alterations of oligodendrocytes at the ultrastructural, genetic, epigenetic and molecular levels [162-164]. Similarly to PV neurons, oligodendrocytes have a high metabolism to build and maintain the myelin sheets around the axons [165] and express elevated antioxidant enzymes (catalase and GPx) to prevent lipid peroxidation [166]. In addition, these glial cells contain elevated levels of iron needed as co-factor for many enzymes implicated in myelin synthesis. These glial cells are therefore particularly vulnerable to OxS. Environmental risk factors for schizophrenia generating OxS affect maturation and maintenance of oligodendrocyte integrity [167]. Thus, a dysregulated homeostasis between energy metabolism and antioxidant machinery may have deleterious effects on the maturation, structural and functional integrity of WM [155]. Of note, oligodendrocytes of schizophrenia patients have reduced volume and number of mitochondria [164].

From a developmental perspective, cellular redox state plays a vital role in maintaining the balance between proliferation and differentiation of oligodendrocyte precursor cells in the developing CNS, with a more oxidized state associated with their differentiation whereas a reduced state promotes their proliferation [168-170]. Thus, a redox dysregulation resulting from a GSH deficit modulates the switch from cell proliferation to early differentiation via alteration of the Fyn kinase pathway and impairs late differentiation [168, 171]. ROS can also inhibit the mTOR-P70S6K signaling cascade leading to decreased protein synthesis for proliferation and differentiation [172]. Of note, post-mortem analysis suggests impaired differentiation of oligodendrocyte precursors in schizophrenia [173]. Likewise, we found that mice with a GSH deficit (Gclm KO) exhibit reduced numbers of mature oligodendrocytes and myelin markers, suggesting that dysregulation of Fyn kinase pathway may underlie these anomalies [168]. In this context, the regulation of Fyn mRNA and protein expression is impaired in fibroblasts from schizophrenia patients with genetic risk for GSH deficit [168]. The importance of GSH is further supported by the positive correlation between patients GSH levels in PFC and structural WM diffusion properties in the cingulum bundle [168]. Other evidence linking GSH deficit to WM stems from a 14T diffusion MRI longitudinal study on Gclm KO mice. This revealed reduced fractional anisotropy within the fornix/fimbria accompanied by a slower conduction velocity along nerve fibers [174]. Similarly WM diffusion properties were decreased in fornix of early psychosis patients, in correlation with a smaller hippocampus volume and elevated blood oxidative status marker [175].

As for PV neurons, complex reciprocal interactions between redox dysregulation/OxS, mitochondria, neuroinflammation, and NMDAR function may generate vicious effects for oligodendrocytes (Fig. 1). The differentiation and integrity of oligodendrocytes require a coordinated regulation of metabolic needs and redox balance to prevent the deleterious effect of OxS, also triggered by neuroinflammation. Oligodendrocytes are vulnerable to early-life neuroinflammation [176, 177] leading to impaired myelination $[167,172,178,179]$. As immune targets and regulators, oligodendrocytes are engaged in multiple cross-talks with 
microglia that include responses to stress which can lead to myelin damages, but also mechanisms of repair [180].

NMDAR dysfunction may also lead to alterations of WM diffusion properties. Indeed, stimulation of NMDARs, expressed in immature and mature oligodendrocytes, promote the maturation of these cells and myelination around axons [181-183], upregulates their energy metabolism, increases mitochondria motility within myelin sheath, and glycolytic support to the axons $[184,185]$. Thus, a dysfunction of NMDARs on oligodendrocytes, which remains speculative in schizophrenia, affects myelination and proper regulation of the energy coupling between oligodendrocytes and axons. This could be especially detrimental for fastspiking neurons such as PV interneurons whose axons are strongly myelinated [186, 187].

\section{A FOCUS ON REDOX DYSREGULATION IN RELATION TO CHILDHOOD TRAUMA}

Evidence supporting the interplay of genetic and environmental factors in relation to liability for schizophrenia stems from human and animal studies. Traumatic experiences occurring during the critical time of childhood and adolescence favors the development of psychiatric disorders associated with psychosis and cognitive impairments [188, 189]. Supported by studies on animal models, some symptoms and cognitive deficits may be directly associated to the deleterious impact of these environmental stresses on PV neurons and oligodendrocytes through the action of OxS. In rats, stress during adolescence, but not adulthood, leads to long-term hyperactivity of the dopaminergic system that is relevant to positive symptoms [190] and is concomitant to deficits of hippocampal PV interneuron-networks [101]. Our data suggests this is due to a high vulnerability of PV interneurons to OxS during childhood and adolescence as opposed to adulthood [81]. Early-life stress increases OxS in prefrontal and hippocampal PV interneurons [191]. Goodwill et al. (2018) [192] also show that early-life stress causes longterm decreased PV expression and density of PV neurons in orbitofrontal cortex which result in impaired rule-reversal learning. Early-life induced persistent decrease of PV expression in PFC is due to HDAC1-dependent epigenetic mechanisms [94]. Likewise, prepubertal stress exacerbates the effects of a previous maternal immune challenge leading to significant OxS, deficits in PV neurons and PNN in PFC [15].

Prenatal stress as well as trauma during childhood and adolescence also affect WM properties [193-195]. However, the impact of stress during these developmental periods on oligodendrocytes is not fully documented. In mice, social isolation through childhood and adolescence, known to affect PV neurons through OxS [83], has also persistent effect on oligodendrocyte morphology and density, and causes reduced expression of myelin-associated proteins and myelin thickness [196]. Altogether, this suggests that redox dysregulation/OxS play a role on the impact of childhood traumatic experiences in patients suffering from schizophrenia.

With this in mind, we assessed a cohort of early psychosis patients in which some had been exposed to severe childhood trauma (sexual and physical abuse). Interestingly, exposure to trauma (particularly when exposed before age of 12 years) is associated with severe positive, negative and depressive symptoms, bad functional and social outcome [197]. This was in contrast to early psychosis patients exposed to trauma after 12 years of age who mostly suffered from negative symptoms and had a similar functional outcome to the non-trauma-exposed early psychosis patients [197, 198]. Among early psychosis patients exposed to childhood trauma, we recently identified two separate groups. One group with high peripheral oxidation status (high GPx activity) displayed smaller hippocampal volumes and more severe symptoms, while the other group with lower oxidation status (low GPx activity) showed better cognition and regulation of GSH- and thioredoxin/peroxiredoxinsystems [199]. These results suggest that maintained regulation of various antioxidant systems allows compensatory mechanisms for mitigating long-term neuroanatomical and clinical impacts. The redox marker profile may thus be useful to define treatment strategies at early stages of psychosis.

\section{FROM BENCH TO BEDSIDE: A FOCUS ON CLINICAL TRIALS WITH N-ACETYL-CYSTEINE (NAC)}

New treatment strategies are increasingly interested in antioxidant compounds such as NAC [200-202]. NAC is reported to have beneficial effects on negative symptoms [203-205] and cognition [205-207] in patients with chronic schizophrenia and with first psychotic episode [208, 209]. It also improved EEG mismatch negativity [210] and local synchronization [211]. In a recent randomized controlled trial on early psychosis patients, we observed that a 6-month NAC add-on treatment significantly increased the levels of GSH in PFC, suggesting a good drug-target engagement [209]. NAC improved neurocognitive-processing speed in correlation with negative symptoms. Interestingly, our study found that NAC could also improve positive symptoms but only in early psychosis patients exhibiting a high blood oxidative status [209]. We have also shown for the first time that NAC administration to early psychosis patients improved WM diffusion properties in fornix. This improvement was correlated with brain GSH increase [212]. In addition, NAC ameliorated low-level auditory processing [213] and resting-state functional connectivity within the cingulum bundle [214]. A single dose monotherapy with NAC reduced medial frontal resting-state functional connectivity [215]. Taken together, these findings open the gateway to biomarker-guided therapy. Nonetheless, further longitudinal studies of antioxidant treatment in larger cohorts of biomarker selected patients, controlled by target engagement, are required.

\section{POTENTIAL INTERVENTIONS FOR BREAKING THE VICIOUS CIRCLES OF OXIDATIVE STRESS}

Interventions/drugs that aim at breaking the different vicious circles causing persistent OxS represent promising strategies to reduce the deleterious effects on PV neurons and myelin-forming oligodendrocytes [14], and therefore mitigate the emergence or severity of the disorder. In this context, one should consider compounds with both anti-oxidative and anti-inflammatory properties (e.g. NAC, sulforaphane, omega-3 polyunsaturated fatty acids) [216], molecules targeting specifically mitochondria (e.g. MitoQ), and positive modulators of NMDAR-mediated signaling (e.g. D-serine, sarcosine, benzoate, glycine transporter inhibitors) [217]. The efficacy of these different compound categories may however differ from patients to patients, according to the timing of initiation during neurodevelopment of the vicious feedforward processes that are primarily triggered and the disease stages (prodrome, first episode or chronic). Biomarker-based approaches, targeting validated mechanisms, will be essential to identify individuals more likely to respond to a specific drug in future clinical trials (Fig. 2).

A question remains: could interventions that manipulate OxS mechanisms be applied for patients exposed to childhood trauma in real world clinic setting? In Gclm KO mice, we recently showed that the sequential combination of NAC treatment and environmental enrichment applied during the juvenile and adolescent periods respectively normalizes the integrity and function of PV neuron/PNN networks induced by an additional oxidative insult during childhood, that mimics childhood adverse events that would induce OxS [143]. NAC, via inhibition of OxS-induced MMP9/RAGE pathway, interrupts the deleterious feedforward mechanism that maintains persisting high OxS levels and neuroinflammation, allowing PVI/PNN maturation (see chapter 5). A subsequent environmental enrichment 


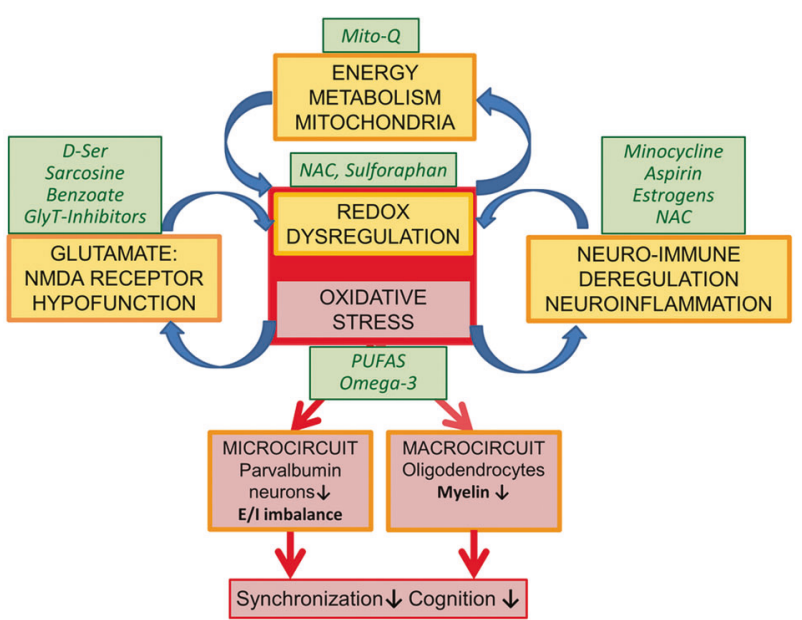

Fig. 2 Potential points of action of various molecules capable of interrupting the diverse vicious circles. a Treatments with compounds such as NAC, sulforaphane or omega-3 type polyunsaturated fatty acids (PUFAS) - which possess both anti-oxidative and anti-inflammatory properties with mild side-effect profiles [202, 218-221] are known to exert their effects through the redox system thus representing good candidates for preventive interventions targeting individuals at high-risk for schizophrenia. Sulforaphane works through the NRF2 system to trigger the anti-oxidant defence system [222]. b MitoQ and other mitochondria-targeted antioxidants could support compromised energy metabolism and mitochondria function [116]. c For NMDAR hypofunction, several strategies using compounds (e.g., D-serine, sarcosine, glycine transporter inhibitor and benzoate) that modulate NMDAR activity have been tried in schizophrenia patients with mixed success [217, 223-229]. d In terms of neuro-inflammation, estrogens, minocycline and NAC showed efficacy, with greater beneficial results on symptom severity in first-episode psychosis patients or during early-phase of schizophrenia [216].

during adolescence promotes the final maturation of PV neurons, providing a long-term neuroprotection to PV neuron/PNN networks. Translating to early psychosis patients, a 6-month NAC treatment reduces plasma sRAGE in association with increased prefrontal GABA, improvement of working memory, processing speed and positive symptoms, suggesting similar neuroprotective mechanisms [143]. Thus, by analogy, in real world clinic, patients exposed to early-life insults may benefit from a biomarker (sRAGE/MMP9)guided antioxidant treatment combined with the equivalent of "environmental enrichment", which could include physical training, nutrition, social activities and psychotherapy.

\section{CONCLUSION}

Collectively the above data support the view that the various genetic and environmental factors impinging on one or more pathological mechanisms involved in schizophrenia, namely anomalies in mitochondria and energy metabolism, NMDAR hypofunction, neuroinflammation will ultimately impair redox regulation leading to OxS and its deleterious consequence on PV neurons and oligodendrocytes. As shown for PV neurons, a redox dysregulation can in turn further promote NMDAR hypofunction, mitochondrial impairment, and neuroinflammation in feedforward vicious circles that perpetuate the persistence of OxS and long-term impact on these highly metabolic cells. Eventually, a primary dysfunction of NMDARs, or neuroinflammation, or mitochondrial dysfunction, or impaired regulation of antioxidant systems could involve in turn the other vicious circles, all converging to common deleterious impacts on PV neurons and oligodendrocytes during neurodevelopment (Fig. 1). In addition to psychotic disorders and schizophrenia, the proposed mechanisms may also be applied to other psychiatric diseases including autism and bipolar disorder.

By adopting the reverse translation of validated circuitryrelevant human endpoints approach [2], we provide convincing proof-of-concept for targeting OxS through antioxidant-based strategies in individuals with schizophrenia and underscore the importance of "breaking" the various vicious circles associated with OxS as means to prevent the propagation of processes that may precede the onset of disease. To improve early detection and increase the signal-to-noise ratio for adjunctive trials of antioxidants, anti-inflammatory and NMDAR modulator drugs, the above presented processes allow to identify mechanismbased biomarkers guiding stratification of homogenous patients groups and target engagement required for successful clinical trials, paving the way towards precision medicine in psychiatry $[90,116,143,209,212]$. Presently, it is not easy to interfere with the genetic component of the disease nor fully prevent the impact of environmental factors. Thus, acting early during development on the vicious circles leading to lasting OxS might be a rewarding strategy to reduce its consequences on key functions of micro- and macro-circuits impairments and their clinical manifestations.

\section{REFERENCES}

1. Fusar-Poli P, Salazar de Pablo G, Correll CU, Meyer-Lindenberg A, Millan MJ, Borgwardt $S$, et al. Prevention of psychosis: advances in detection, prognosis, and intervention. JAMA Psychiatry. 2020;77:755-65.

2. O'Donnell P, Rosen L, Alexander R, Murthy V, Davies CH, Ratti E. Strategies to address challenges in neuroscience drug discovery and development. Int $\mathrm{J}$ Neuropsychopharmacol. 2019;22:445-8.

3. Murray RM, Lewis SW. Is schizophrenia a neurodevelopmental disorder? Br Med J. 1987;295:681-2.

4. Weinberger DR. Implications of normal brain development for the pathogenesis of schizophrenia. Arch Gen Psychiatry. 1987;44:660-9.

5. Howes O, McCutcheon R, Stone J. Glutamate and dopamine in schizophrenia: an update for the 21st century. J Psychopharmacol. 2015;29:97-115.

6. Nakazawa K, Sapkota K. The origin of NMDA receptor hypofunction in schizophrenia. Pharm Ther. 2020;205:107426.

7. Kirkpatrick B, Miller BJ. Inflammation and schizophrenia. Schizophr Bull. 2013;39:1174-9.

8. Rajasekaran A, Venkatasubramanian G, Berk M, Debnath M. Mitochondrial dysfunction in schizophrenia: pathways, mechanisms and implications. Neurosci Biobehav Rev. 2015;48:10-21.

9. Sekar A, Bialas AR, de Rivera H, Davis A, Hammond TR, Kamitaki N, et al. Schizophrenia risk from complex variation of complement component 4. Nature 2016;530:177-83.

10. Sellgren CM, Gracias J, Watmuff B, Biag JD, Thanos JM, Whittredge PB, et al. Increased synapse elimination by microglia in schizophrenia patient-derived models of synaptic pruning. Nat Neurosci. 2019;22:374-85.

11. Takahashi N, Sakurai T, Davis KL, Buxbaum JD. Linking oligodendrocyte and myelin dysfunction to neurocircuitry abnormalities in schizophrenia. Prog Neurobiol. 2011;93:13-24.

12. Taylor SF, Tso IF. GABA abnormalities in schizophrenia: a methodological review of in vivo studies. Schizophr Res. 2015;167:84-90.

13. Do KQ, Cabungcal JH, Frank A, Steullet P, Cuenod M. Redox dysregulation, neurodevelopment, and schizophrenia. Curr Opin Neurobiol. 2009;19:220-30.

14. Steullet $P$, Cabungcal JH, Monin A, Dwir D, O'Donnell P, Cuenod M, et al. Redox dysregulation, neuroinflammation, and NMDA receptor hypofunction: A "central hub" in schizophrenia pathophysiology? Schizophr Res. 2016;176:41-51.

15. Steullet P, Cabungcal JH, Coyle J, Didriksen M, Gill K, Grace AA, et al. Oxidative stress-driven parvalbumin interneuron impairment as a common mechanism in models of schizophrenia. Mol Psychiatry. 2017;22:936-43.

16. Jones DP, Sies H. The redox code. Antioxid Redox Signal. 2015;23:734-46.

17. Jones DP. Redox sensing: orthogonal control in cell cycle and apoptosis signalling. J Intern Med. 2010;268:432-48.

18. Perkins DO, Jeffries $C D$, Do KQ. Potential roles of redox dysregulation in the development of schizophrenia. Biol Psychiatry. 2020;88:326-36.

19. Fernandez A, Meechan DW, Karpinski BA, Paronett EM, Bryan CA, Rutz HL, et al. Mitochondrial dysfunction leads to cortical under-connectivity and cognitive impairment. Neuron 2019;102:1127-42.e3. 
20. Hardingham GE, Do KQ. Linking early-life NMDAR hypofunction and oxidative stress in schizophrenia pathogenesis. Nat Rev Neurosci. 2016;17:125-34.

21. Do KQ, Lauer CJ, Schreiber W, Zollinger M, Gutteck-Amsler U, Cuénod M, et al. gamma-Glutamylglutamine and taurine concentrations are decreased in the cerebrospinal fluid of drug-naive patients with schizophrenic disorders. J Neurochem. 1995;65:2652-62.

22. Do KQ, Trabesinger AH, Kirsten-Krüger M, Lauer $C J$, Dydak $U$, Hell $D$, et al. Schizophrenia: glutathione deficit in cerebrospinal fluid and prefrontal cortex in vivo. Eur J Neurosci. 2000;12:3721-28.

23. Do KQ, Bovet $\mathrm{P}$, Cabungcal JH, Conus $\mathrm{P}$, Gysin R, Lavoie $\mathrm{S}$, et al. Redox Dysregulation in Schizophrenia: Genetic susceptibility and pathophysiological mechanisms. In: Lajtha A, Javitt DC, Krantrowitz JT (eds). Handbook of Neurochemistry and Molecular Neurobiology. Schizophrenia. Springer:New York, 2009, pp 285-311.

24. Flatow J, Buckley P, Miller BJ. Meta-analysis of oxidative stress in schizophrenia. Biol Psychiatry. 2013;74:400-9.

25. Koga M, Serritella AV, Sawa A, Sedlak TW. Implications for reactive oxygen species in schizophrenia pathogenesis. Schizophr Res. 2016;176:52-71.

26. Tsugawa S, Noda Y, Tarumi R, Mimura Y, Yoshida K, Iwata Y, et al. Glutathione levels and activities of glutathione metabolism enzymes in patients with schizophrenia: a systematic review and meta-analysis. J Psychopharmacol. 2019;33:1199-214.

27. Yao JK, Keshavan MS. Antioxidants, redox signaling, and pathophysiology in schizophrenia: an integrative view. Antioxid Redox Signal. 2011;15:2011-35.

28. Gysin R, Kraftsik R, Sandell J, Bovet P, Chappuis C, Conus P, et al. Impaired glutathione synthesis in schizophrenia: convergent genetic and functional evidence. Proc Natl Acad Sci USA. 2007;104:16621-6.

29. Tosic M, Ott J, Barral S, Bovet P, Deppen P, Gheorghita F, et al. Schizophrenia and oxidative stress: glutamate cysteine ligase modifier as a susceptibility gene. Am J Hum Genet. 2006;79:586-92.

30. Gravina P, Spoletini I, Masini S, Valentini A, Vanni D, Paladini E, et al. Genetic polymorphisms of glutathione S-transferases GSTM1, GSTT1, GSTP1 and GSTA1 as risk factors for schizophrenia. Psychiatry Res. 2011;187:454-6.

31. Rodríguez-Santiago B, Brunet A, Sobrino B, Serra-Juhé C, Flores R, Armengol L, et al. Association of common copy number variants at the glutathione S-transferase genes and rare novel genomic changes with schizophrenia. Mol Psychiatry. 2010;15:1023-33.

32. Akyol O, Yanik M, Elyas $H$, Namli M, Canatan $H$, Akin $H$, et al. Association between Ala-9Val polymorphism of $\mathrm{Mn}-\mathrm{SOD}$ gene and schizophrenia. Prog Neuropsychopharmacol Biol Psychiatry. 2005;29:123-31.

33. Brzustowicz LM, Simone J, Mohseni P, Hayter JE, Hodgkinson KA, Chow EW, et al. Linkage disequilibrium mapping of schizophrenia susceptibility to the CAPON region of chromosome 1q22. Am J Hum Genet. 2004;74:1057-63.

34. Reif A, Herterich $S$, Strobel A, Ehlis AC, Saur D, Jacob CP, et al. A neuronal nitric oxide synthase (NOS-I) haplotype associated with schizophrenia modifies prefrontal cortex function. Mol Psychiatry. 2006;11:286-300.

35. Gysin R, Kraftsik R, Boulat O, Bovet P, Conus P, Comte-Krieger E, et al. Genetic dysregulation of glutathione synthesis predicts alteration of plasma thiol redox status in schizophrenia. Antioxid Redox Signal. 2011;15:2003-10.

36. Xin L, Mekle R, Fournier M, Baumann PS, Ferrari C, Alameda L, et al. Genetic polymorphism associated prefrontal glutathione and its coupling with brain glutamate and peripheral redox status in early psychosis. Schizophr Bull. 2016;42:1185-96.

37. Kebir O, Chaumette B, Rivollier F, Miozzo F, Lemieux Perreault LP, Barhdadi A et al. Methylomic changes during conversion to psychosis. Mol Psychiatry. 2017;22:512-8.

38. Kumar J, Liddle EB, Fernandes CC, Palaniyappan L, Hall EL, Robson SE, et al. Glutathione and glutamate in schizophrenia: a 7T MRS study. Mol Psychiatry. 2020:25:873-82.

39. Wang AM, Pradhan S, Coughlin JM, Trivedi A, DuBois SL, Crawford JL, et al. Assessing brain metabolism with 7-T proton magnetic resonance spectroscopy in patients with first-episode psychosis. JAMA Psychiatry. 2019;76:314-23.

40. Matsuzawa D, Obata T, Shirayama Y, Nonaka H, Kanazawa Y, Yoshitome E, et al. Negative correlation between brain glutathione level and negative symptoms in schizophrenia: a 3T 1H-MRS study. PLoS ONE. 2008;3:e1944.

41. Terpstra M, Vaughan TJ, Ugurbil K, Lim KO, Schulz SC, Gruetter R. Validation of glutathione quantitation from STEAM spectra against edited $1 \mathrm{H}$ NMR spectroscopy at 4T: application to schizophrenia. Magma 2005;18:276-82

42. Das TK, Javadzadeh A, Dey A, Sabesan P, Théberge J, Radua J, et al. Antioxidant defense in schizophrenia and bipolar disorder: a meta-analysis of MRS studies of anterior cingulate glutathione. Prog Neuropsychopharmacol Biol Psychiatry. 2019;91:94-102.

43. Sydnor VJ, Roalf DR. A meta-analysis of ultra-high field glutamate, glutamine, GABA and glutathione 1HMRS in psychosis: Implications for studies of psychosis risk. Schizophr Res. 2020;226:61-9.

44. Dempster K, Jeon P, MacKinley M, Williamson P, Théberge J, Palaniyappan L. Early treatment response in first episode psychosis: a 7-T magnetic resonance spectroscopic study of glutathione and glutamate. Mol Psychiatry 2020;25: 1640-50.

45. Gawryluk JW, Wang JF, Andreazza AC, Shao L, Young LT. Decreased levels of glutathione, the major brain antioxidant, in post-mortem prefrontal cortex from patients with psychiatric disorders. Int J Neuropsychopharmacol. 2011;14:123-30.

46. Yao JK, Leonard S, Reddy R. Altered glutathione redox state in schizophrenia. Dis Markers. 2006;22:83-93.

47. Zhang Y, Catts VS, Shannon Weickert C. Lower antioxidant capacity in the prefrontal cortex of individuals with schizophrenia. Aust N. Z J Psychiatry. 2018;52:690-8.

48. Raffa M, Atig F, Mhalla A, Kerkeni A, Mechri A. Decreased glutathione levels and impaired antioxidant enzyme activities in drug-naive first-episode schizophrenic patients. BMC Psychiatry. 2011;11:124.

49. Lewis DA, Curley AA, Glausier JR, Volk DW. Cortical parvalbumin interneurons and cognitive dysfunction in schizophrenia. Trends Neurosci. 2012;35:57-67.

50. Konradi C, Yang CK, Zimmerman El, Lohmann KM, Gresch P, Pantazopoulos H, et al. Hippocampal interneurons are abnormal in schizophrenia. Schizophr Res. 2011;131:165-73.

51. Zhang ZJ, Reynolds GP. A selective decrease in the relative density of parvalbumin-immunoreactive neurons in the hippocampus in schizophrenia. Schizophr Res. 2002;55:1-10.

52. Enwright JF, Sanapala S, Foglio A, Berry R, Fish KN, Lewis DA. Reduced labeling of parvalbumin neurons and perineuronal nets in the dorsolateral prefrontal cortex of subjects with schizophrenia. Neuropsychopharmacology 2016;41:2206-14.

53. Bernstein HG, Krause S, Krell D, Dobrowolny H, Wolter M, Stauch R, et al. Strongly reduced number of parvalbumin-immunoreactive projection neurons in the mammillary bodies in schizophrenia: further evidence for limbic neuropathology. Ann N. Y Acad Sci. 2007;1096:120-7.

54. Kilonzo VW, Sweet RA, Glausier JR, Pitts MW. Deficits in glutamic acid decarboxylase 67 immunoreactivity, parvalbumin interneurons, and perineuronal nets in the inferior colliculus of subjects with schizophrenia. Schizophr Bull. 2020;46:1053-9.

55. Pantazopoulos H, Woo TU, Lim MP, Lange N, Berretta S. Extracellular matrix-glial abnormalities in the amygdala and entorhinal cortex of subjects diagnosed with schizophrenia. Arch Gen Psychiatry. 2010;67:155-66.

56. Steullet $\mathrm{P}$, Cabungcal JH, Bukhari SA, Ardelt MI, Pantazopoulos $\mathrm{H}$, Hamati F, et al. The thalamic reticular nucleus in schizophrenia and bipolar disorder: role of parvalbumin-expressing neuron networks and oxidative stress. Mol Psychiatry. 2018;23:2057-65.

57. Tsubomoto M, Kawabata R, Zhu X, Minabe $Y$, Chen K, Lewis DA, et al. Expression of transcripts selective for GABA neuron subpopulations across the cortical visuospatial working memory network in the healthy state and schizophrenia. Cereb Cortex. 2019;29:3540-50.

58. Hashimoto T, Bazmi HH, Mirnics K, Wu Q, Sampson AR, Lewis DA. Conserved regional patterns of GABA-related transcript expression in the neocortex of subjects with schizophrenia. Am J Psychiatry. 2008;165:479-89.

59. Maloku E, Covelo IR, Hanbauer I, Guidotti A, Kadriu B, Hu Q, et al. Lower number of cerebellar Purkinje neurons in psychosis is associated with reduced reelin expression. Proc Natl Acad Sci USA. 2010;107:4407-11.

60. Gonzalez-Burgos G, Cho RY, Lewis DA. Alterations in cortical network oscillations and parvalbumin neurons in schizophrenia. Biol Psychiatry. 2015;77:1031-40.

61. Thankachan S, Katsuki F, McKenna JT, Yang C, Shukla C, Deisseroth K, et al. Thalamic reticular nucleus parvalbumin neurons regulate sleep spindles and electrophysiological aspects of schizophrenia in mice. Sci Rep. 2019;9:3607.

62. Bicks LK, Yamamuro K, Flanigan ME, Kim JM, Kato D, Lucas EK, et al. Prefrontal parvalbumin interneurons require juvenile social experience to establish adult social behavior. Nat Commun. 2020;11:1003.

63. Deverett B, Kislin M, Tank DW, Wang SS. Cerebellar disruption impairs working memory during evidence accumulation. Nat Commun. 2019;10:3128.

64. Gutierrez-Castellanos N, Da Silva-Matos CM, Zhou K, Canto CB, Renner MC, Koene $\mathrm{LMC}$, et al. Motor learning requires Purkinje cell synaptic potentiation through activation of AMPA-receptor subunit GluA3. Neuron 2017;93:409-24.

65. $\mathrm{Hu} \mathrm{H}$, Gan J. Jonas P. Interneurons. Fast-spiking, parvalbumin ${ }^{+}$GABAergic interneurons: from cellular design to microcircuit function. Science 2014;345:1255263.

66. Kim H, Ährlund-Richter S, Wang X, Deisseroth K, Carlén M. Prefrontal parvalbumin neurons in control of attention. Cell 2016;164:208-18.

67. Perez SM, Boley A, Lodge DJ. Region specific knockdown of Parvalbumin or Somatostatin produces neuronal and behavioral deficits consistent with those observed in schizophrenia. Transl Psychiatry. 2019;9:264.

68. Wolff SB, Gründemann J, Tovote P, Krabbe S, Jacobson GA, Müller C, et al. Amygdala interneuron subtypes control fear learning through disinhibition. Nature 2014;509:453-8.

69. Lodge DJ, Grace AA. Hippocampal dysfunction and disruption of dopamine system regulation in an animal model of schizophrenia. Neurotox Res. 2008; 14:97-104. 
70. Blurton-Jones M, Tuszynski MH. Estrogen receptor-beta colocalizes extensively with parvalbumin-labeled inhibitory neurons in the cortex, amygdala, basal forebrain, and hippocampal formation of intact and ovariectomized adult rats. J Comp Neurol. 2002;452:276-87.

71. Niessing J, Ebisch B, Schmidt KE, Niessing M, Singer W, Galuske RA. Hemodynamic signals correlate tightly with synchronized gamma oscillations. Science 2005;309:948-51.

72. Kann O, Huchzermeyer C, Kovács R, Wirtz S, Schuelke M. Gamma oscillations in the hippocampus require high complex I gene expression and strong functional performance of mitochondria. Brain 2011;134:345-58.

73. Harris JJ, Jolivet R, Attwell D. Synaptic energy use and supply. Neuron 2012;75:762-77.

74. Van Derveer AB, Bastos G, Ferrell AD, Gallimore CG, Greene ML, Holmes JT, et al. A role for somatostatin-positive interneurons in neuro-oscillatory and information processing deficits in schizophrenia. Schizophr Bull. 2020;47:1385-98.

75. Wong FK, Bercsenyi K, Sreenivasan V, Portalés A, Fernández-Otero M, Marín O. Pyramidal cell regulation of interneuron survival sculpts cortical networks. Nature 2018;557:668-73.

76. Behrens MM, Ali SS, Dao DN, Lucero J, Shekhtman G, Quick KL, et al. Ketamineinduced loss of phenotype of fast-spiking interneurons is mediated by NADPHoxidase. Science 2007;318:1645-7.

77. Cabungcal JH, Steullet $P$, Kraftsik R, Cuenod M, Do KQ. A developmental redox dysregulation leads to spatio-temporal deficit of parvalbumin neuron circuitry in a schizophrenia mouse model. Schizophr Res. 2019;213:96-106.

78. Pitts MW, Raman AV, Hashimoto AC, Todorovic C, Nichols RA, Berry MJ. Deletion of selenoprotein $\mathrm{P}$ results in impaired function of parvalbumin interneurons and alterations in fear learning and sensorimotor gating. Neuroscience 2012;208:58-68.

79. Cabungcal JH, Steullet P, Kraftsik R, Cuenod M, Do KQ. Early-life insults impair parvalbumin interneurons via oxidative stress: reversal by $\mathrm{N}$-acetylcysteine. Biol Psychiatry. 2013;73:574-82.

80. Phensy A, Driskill C, Lindquist K, Guo L, Jeevakumar V, Fowler B, et al. Antioxidant treatment in male mice prevents mitochondrial and synaptic changes in an NMDA receptor dysfunction model of schizophrenia. ENeuro. 2017:4:e0081-17.

81. Cabungcal JH, Steullet P, Morishita H, Kraftsik R, Cuenod M, Hensch TK, et al. Perineuronal nets protect fast-spiking interneurons against oxidative stress. Proc Natl Acad Sci USA. 2013;110:9130-5.

82. Steullet $P$, Cabungcal JH, Kulak A, Kraftsik R, Chen Y, Dalton TP, et al. Redox dysregulation affects the ventral but not dorsal hippocampus: impairment of parvalbumin neurons, gamma oscillations, and related behaviors. J Neurosci. 2010;30:2547-58.

83. Schiavone $S$, Sorce $S$, Dubois-Dauphin $M$, Jaquet V, Colaianna M, Zotti M, et al. Involvement of NOX2 in the development of behavioral and pathologic alterations in isolated rats. Biol Psychiatry. 2009;66:384-92.

84. Cabungcal JH, Counotte DS, Lewis E, Tejeda HA, Piantadosi P, Pollock C, et al. Juvenile antioxidant treatment prevents adult deficits in a developmental model of schizophrenia. Neuron 2014;83:1073-84.

85. Cabungcal JH, Nicolas D, Kraftsik R, Cuénod M, Do KQ, Hornung JP. Glutathione deficit during development induces anomalies in the rat anterior cingulate GABAergic neurons: relevance to schizophrenia. Neurobiol Dis. 2006;22:624-37.

86. Kulak A, Steullet $P$, Cabungcal JH, Werge T, Ingason A, Cuenod M, et al. Redox dysregulation in the pathophysiology of schizophrenia and bipolar disorder: insights from animal models. Antioxid Redox Signal. 2013;18:1428-43.

87. Steullet $P$, Cabungcal JH, Kulak A, Cuenod M, Schenk F, Do KQ Glutathione deficit in animal models of schizophrenia. In: O'Donnell P (ed). Animal models of schizophrenia and related disorders. Humana Press:New York, 2011, pp 149-88.

88. Beurdeley M, Spatazza J, Lee HH, Sugiyama S, Bernard C, Di Nardo AA, et al. Otx2 binding to perineuronal nets persistently regulates plasticity in the mature visual cortex. J Neurosci. 2012;32:9429-37.

89. Miyata S, Komatsu Y, Yoshimura Y, Taya C, Kitagawa H. Persistent cortical plasticity by upregulation of chondroitin 6-sulfation. Nat Neurosci. 2012;15:414-22.

90. Dwir D, Giangreco B, Xin L, Tenenbaum L, Cabungcal JH, Steullet P, et al. MMP9/ RAGE pathway overactivation mediates redox dysregulation and neuroinflammation, leading to inhibitory/excitatory imbalance: a reverse translation study in schizophrenia patients. Mol Psychiatry. 2020;25:2889-904.

91. Wen TH, Binder DK, Ethell IM, Razak KA. The perineuronal 'Safety' net? Perineuronal net abnormalities in neurological disorders. Front Mol Neurosci. 2018;11:270.

92. Gandal MJ, Nesbitt AM, McCurdy RM, Alter MD. Measuring the maturity of the fast-spiking interneuron transcriptional program in autism, schizophrenia, and bipolar disorder. PLoS ONE. 2012;7:e41215.

93. Pietersen CY, Mauney SA, Kim SS, Passeri E, Lim MP, Rooney RJ, et al. Molecular profiles of parvalbumin-immunoreactive neurons in the superior temporal cortex in schizophrenia. J Neurogenet. 2014;28:70-85.

94. Bahari-Javan S, Varbanov H, Halder R, Benito E, Kaurani L, Burkhardt S, et al. HDAC1 links early life stress to schizophrenia-like phenotypes. Proc Natl Acad Sci USA. 2017;114:E4686-94.
95. Fachim HA, Srisawat U, Dalton CF, Reynolds GP. Parvalbumin promoter hypermethylation in postmortem brain in schizophrenia. Epigenomics 2018; 10:519-24.

96. Lodge DJ, Behrens MM, Grace AA. A loss of parvalbumin-containing interneurons is associated with diminished oscillatory activity in an animal model of schizophrenia. J Neurosci. 2009;29:2344-54.

97. Penschuck S, Flagstad P, Didriksen $M$, Leist $M$, Michael-Titus AT. Decrease in parvalbumin-expressing neurons in the hippocampus and increased phencyclidine-induced locomotor activity in the rat methylazoxymethanol (MAM) model of schizophrenia. Eur J Neurosci. 2006;23:279-84.

98. Fonnum F, Lock EA. The contributions of excitotoxicity, glutathione depletion and DNA repair in chemically induced injury to neurones: exemplified with toxic effects on cerebellar granule cells. J Neurochem. 2004;88:513-31.

99. Bittle J, Menezes EC, McCormick ML, Spitz DR, Dailey M, Stevens HE. The role of redox dysregulation in the effects of prenatal stress on embryonic interneuron migration. Cereb Cortex. 2019;29:5116-30.

100. Morishita H, Cabungcal JH, Chen Y, Do KQ, Hensch TK. Prolonged period of cortical plasticity upon redox dysregulation in fast-spiking interneurons. Biol Psychiatry. 2015;78:396-402.

101. Gomes FV, Zhu X, Grace AA. The pathophysiological impact of stress on the dopamine system is dependent on the state of the critical period of vulnerability. Mol Psychiatry. 2020;25:3278-91.

102. Do KQ, Cuenod M, Hensch TK. Targeting oxidative stress and aberrant critical period plasticity in the developmental trajectory to schizophrenia. Schizophr Bull. 2015;41:835-46.

103. Arion D, Huo Z, Enwright JF, Corradi JP, Tseng G, Lewis DA. Transcriptome alterations in prefrontal pyramidal cells distinguish schizophrenia from bipolar and major depressive disorders. Biol Psychiatry. 2017;82:594-600.

104. Ben-Shachar D. Mitochondrial multifaceted dysfunction in schizophrenia; complex I as a possible pathological target. Schizophr Res. 2017;187:3-10.

105. Iwamoto K, Bundo M, Kato T. Altered expression of mitochondria-related genes in postmortem brains of patients with bipolar disorder or schizophrenia, as revealed by large-scale DNA microarray analysis. Hum Mol Genet. 2005;14:241-53.

106. Kano S, Colantuoni C, Han F, Zhou Z, Yuan Q, Wilson A, et al. Genomewide profiling of multiple histone methylations in olfactory cells: further implications for cellular susceptibility to oxidative stress in schizophrenia. Mol Psychiatry. 2013;18:740-2.

107. Prabakaran S, Swatton JE, Ryan MM, Huffaker SJ, Huang JT, Griffin JL, et al. Mitochondrial dysfunction in schizophrenia: evidence for compromised brain metabolism and oxidative stress. Mol Psychiatry. 2004;9:684-97.

108. Robicsek O, Karry R, Petit I, Salman-Kesner N, Müller FJ, Klein E, et al. Abnormal neuronal differentiation and mitochondrial dysfunction in hair follicle-derived induced pluripotent stem cells of schizophrenia patients. Mol Psychiatry. 2013;18:1067-76.

109. Rollins BL, Morgan L, Hjelm BE, Sequeira A, Schatzberg AF, Barchas JD, et al. Mitochondrial complex I deficiency in schizophrenia and bipolar disorder and medication influence. Mol Neuropsychiatry. 2018;3:157-69.

110. Du F, Cooper AJ, Thida T, Sehovic S, Lukas SE, Cohen BM, et al. In vivo evidence for cerebral bioenergetic abnormalities in schizophrenia measured using 31P magnetization transfer spectroscopy. JAMA Psychiatry. 2014;71:19-27.

111. Enwright lii JF, Huo Z, Arion D, Corradi JP, Tseng G, Lewis DA. Transcriptome alterations of prefrontal cortical parvalbumin neurons in schizophrenia. Mol Psychiatry. 2018;23:1606-13.

112. Ni P, Noh H, Park GH, Shao Z, Guan Y, Park JM, et al. iPSC-derived homogeneous populations of developing schizophrenia cortical interneurons have compromised mitochondrial function. Mol Psychiatry. 2020;25:2873-88.

113. Ghezzi P, Floridi L, Boraschi D, Cuadrado A, Manda G, Levic S, et al. Oxidative stress and inflammation induced by environmental and psychological stressors: a biomarker perspective. Antioxid Redox Signal. 2018;28:852-72.

114. Kann O. The interneuron energy hypothesis: implications for brain disease. Neurobiol Dis. 2016;90:75-85.

115. Lichvarova L, Henzi T, Safiulina D, Kaasik A, Schwaller B. Parvalbumin alters mitochondrial dynamics and affects cell morphology. Cell Mol Life Sci. 2018;75:4643-66.

116. Khadimallah I, Jenni R, Cabungcal JH, Cleusix M, Fournier M, Klauser $P$, et al. Mitochondrial, exosomal miR137-COX6A2 and gamma synchrony as biomarkers of parvalbumin interneurons, psychopathology and neurocognition in schizophrenia. Mol Psychiatry. https://doi.org/10.1038/s41380-021-01313-9. (in press)

117. Schizophrenia Working Group of the Psychiatric Genomics Consortium. Biological insights from 108 schizophrenia-associated genetic loci. Nature. 2014:511:421-7.

118. Coyle JT, Ruzicka WB, Balu DT. Fifty years of research on schizophrenia: the ascendance of the glutamatergic synapse. Am J Psychiatry. 2020;177:1119-28.

119. Masdeu JC, Dalmau J, Berman KF. NMDA receptor internalization by autoantibodies: a reversible mechanism underlying psychosis? Trends Neurosci. 2016;39:300-10. 
120. Kirov G, Pocklington AJ, Holmans $P$, Ivanov D, Ikeda $M$, Ruderfer D, et al. De novo CNV analysis implicates specific abnormalities of postsynaptic signalling complexes in the pathogenesis of schizophrenia. Mol Psychiatry. 2012;17:142-53.

121. Timms AE, Dorschner MO, Wechsler J, Choi KY, Kirkwood R, Girirajan S, et al. Support for the $\mathrm{N}$-methyl-D-aspartate receptor hypofunction hypothesis of schizophrenia from exome sequencing in multiplex families. JAMA Psychiatry. 2013;70:582-90.

122. Grayson B, Barnes SA, Markou A, Piercy C, Podda G, Neill JC. Postnatal phencyclidine (PCP) as a neurodevelopmental animal model of schizophrenia pathophysiology and symptomatology: a review. Curr Top Behav Neurosci. 2016;29:403-28.

123. Phensy A, Duzdabanian HE, Brewer S, Panjabi A, Driskill C, Berz A, et al. Antioxidant treatment with $\mathrm{N}$-acetyl cysteine prevents the development of cognitive and social behavioral deficits that result from perinatal ketamine treatment. Front Behav Neurosci. 2017;11:106.

124. Stefani MR, Moghaddam B. Transient N-methyl-D-aspartate receptor blockade in early development causes lasting cognitive deficits relevant to schizophrenia. Biol Psychiatry. 2005;57:433-6.

125. Abekawa T, Ito K, Nakagawa S, Koyama T. Prenatal exposure to an NMDA receptor antagonist, MK-801 reduces density of parvalbumin-immunoreactive GABAergic neurons in the medial prefrontal cortex and enhances phencyclidine-induced hyperlocomotion but not behavioral sensitization to methamphetamine in postpubertal rats. Psychopharmacology. 2007;192:303-16.

126. Powell SB, Sejnowski TJ, Behrens MM. Behavioral and neurochemical consequences of cortical oxidative stress on parvalbumin-interneuron maturation in rodent models of schizophrenia. Neuropharmacology 2012;62:1322-31.

127. Aguilar DD, Radzik LK, Schiffino FL, Folorunso OO, Zielinski MR, Coyle JT, et al. Altered neural oscillations and behavior in a genetic mouse model of NMDA receptor hypofunction. Sci Rep. 2021;11:9031

128. Matta JA, Pelkey KA, Craig MT, Chittajallu R, Jeffries BW, McBain CJ. Developmental origin dictates interneuron AMPA and NMDA receptor subunit composition and plasticity. Nat Neurosci. 2013;16:1032-41.

129. Zhang Z, Sun QQ. Development of NMDA NR2 subunits and their roles in critical period maturation of neocortical GABAergic interneurons. Dev Neurobiol. 2011;71:221-45.

130. Cardis R, Cabungcal JH, Dwir D, Do KQ, Steullet P. A lack of GluN2A-containing NMDA receptors confers a vulnerability to redox dysregulation: Consequences on parvalbumin interneurons, and their perineuronal nets. Neurobiol Dis. 2018; 109:64-75.

131. Jiang Z, Rompala GR, Zhang S, Cowell RM, Nakazawa K. Social isolation exacerbates schizophrenia-like phenotypes via oxidative stress in cortical interneurons. Biol Psychiatry. 2013;73:1024-34.

132. Papadia S, Soriano FX, Léveillé $F$, Martel MA, Dakin KA, Hansen $H H$, et al. Synaptic NMDA receptor activity boosts intrinsic antioxidant defenses. Nat Neurosci. 2008;11:476-87.

133. Baxter PS, Bell KF, Hasel $P$, Kaindl AM, Fricker M, Thomson D, et al. Synaptic NMDA receptor activity is coupled to the transcriptional control of the glutathione system. Nat Commun. 2015;6:6761.

134. Choi Y, Chen HV, Lipton SA. Three pairs of cysteine residues mediate both redox and zn2+ modulation of the nmda receptor. J Neurosci. 2001;21:392-400.

135. Köhr G, Eckardt S, Lüddens H, Monyer H, Seeburg PH. NMDA receptor channels: subunit-specific potentiation by reducing agents. Neuron 1994;12:1031-40.

136. Bodhinathan K, Kumar A, Foster TC. Intracellular redox state alters NMDA receptor response during aging through $\mathrm{Ca} 2+/$ calmodulin-dependent protein kinase II. J Neurosci. 2010;30:1914-24.

137. Steullet $P$, Neijt HC, Cuénod $M$, Do KQ. Synaptic plasticity impairment and hypofunction of NMDA receptors induced by glutathione deficit: relevance to schizophrenia. Neuroscience 2006;137:807-19.

138. Bitanihirwe BK, Woo TU. Oxidative stress in schizophrenia: an integrated approach. Neurosci Biobehav Rev. 2011;35:878-93.

139. Fillman SG, Cloonan N, Miller LC, Weickert CS. Markers of inflammation in the prefrontal cortex of individuals with schizophrenia. Mol Psychiatry. 2013;18:133.

140. Khandaker GM, Cousins L, Deakin J, Lennox BR, Yolken R, Jones PB. Inflammation and immunity in schizophrenia: implications for pathophysiology and treatment. Lancet Psychiatry. 2015;2:258-70.

141. Cheslack-Postava K, Brown AS Prenatal infection and schizophrenia: a decade of further progress. Schizophr Res. 2021; https://doi.org/10.1016/j.schres.2021.05.014.

142. Nettis MA, Pariante CM, Mondelli V. Early-life adversity, systemic inflammation and comorbid physical and psychiatric illnesses of adult life. Curr Top Behav Neurosci. 2020;44:207-25.

143. Dwir D, Cabungcal JH, Xin L, Giangreco B, Parietti E, Cleusix M, et al. Timely Nacetyl-cysteine and environmental enrichment rescue oxidative stress-induced parvalbumin interneuron impairments via MMP9/RAGE pathway: a translational approach for early Intervention in psychosis. Schizophr Bull. 2021; https://doi. org/10.1093/schbul/sbab066.
144. Howes OD, Montgomery AJ, Asselin MC, Murray RM, Valli I, Tabraham P, et al. Elevated striatal dopamine function linked to prodromal signs of schizophrenia. Arch Gen Psychiatry. 2009;66:13-20.

145. Howes O, Bose S, Turkheimer F, Valli I, Egerton A, Stahl D, et al. Progressive increase in striatal dopamine synthesis capacity as patients develop psychosis: a PET study. Mol Psychiatry. 2011;16:885-6.

146. Basma AN, Morris EJ, Nicklas WJ, Geller HM. L-dopa cytotoxicity to PC12 cells in culture is via its autoxidation. J Neurochem. 1995;64:825-32.

147. Graham DG, Tiffany SM, Bell WR Jr., Gutknecht WF. Autoxidation versus covalent binding of quinones as the mechanism of toxicity of dopamine, 6-hydroxydopamine, and related compounds toward C1300 neuroblastoma cells in vitro. Mol Pharm. 1978;14:644-53.

148. Grima G, Benz B, Parpura V, Cuénod M, Do KQ. Dopamine-induced oxidative stress in neurons with glutathione deficit: implication for schizophrenia. Schizophr Res. 2003;62:213-24.

149. Glantz LA, Lewis DA. Decreased dendritic spine density on prefrontal cortical pyramidal neurons in schizophrenia. Arch Gen Psychiatry. 2000;57:65-73.

150. Konopaske GT, Lange N, Coyle JT, Benes FM. Prefrontal cortical dendritic spine pathology in schizophrenia and bipolar disorder. JAMA Psychiatry. 2014;71:1323-31.

151. Grace AA. Dopamine system dysregulation and the pathophysiology of schizophrenia: insights from the methylazoxymethanol acetate model. Biol Psychiatry. 2017;81:5-8.

152. Lodge DJ, Grace AA. Hippocampal dysregulation of dopamine system function and the pathophysiology of schizophrenia. Trends Pharm Sci. 2011;32: 507-13.

153. Zhu X, Cabungcal JH, Cuenod M, Uliana DL, Do KQ, Grace AA Thalamic reticular nucleus impairments and abnormal prefrontal control of dopamine system in a developmental model of schizophrenia: prevention by $\mathrm{N}$-acetylcysteine. Mol Psychiatry. 2021; https://doi.org/10.1038/s41380-021-01198-8.

154. O'Donnell P, Grace AA. Dysfunctions in multiple interrelated systems as the neurobiological bases of schizophrenic symptom clusters. Schizophr Bull. 1998; 24:267-83.

155. Juurlink $\mathrm{BH}$, Thorburne SK, Hertz L. Peroxide-scavenging deficit underlies oligodendrocyte susceptibility to oxidative stress. Glia 1998;22:371-8.

156. Kelly S, Jahanshad N, Zalesky A, Kochunov P, Agartz I, Alloza C, et al. Widespread white matter microstructural differences in schizophrenia across 4322 individuals: results from the ENIGMA Schizophrenia DTI Working Group. Mol Psychiatry. 2018;23:1261-9.

157. Kubicki M, Shenton ME. Diffusion Tensor Imaging findings and their implications in schizophrenia. Curr Opin Psychiatry. 2014;27:179-84.

158. Griffa A, Baumann PS, Klauser P, Mullier E, Cleusix M, Jenni R, et al. Brain connectivity alterations in early psychosis: from clinical to neuroimaging staging. Transl Psychiatry. 2019;9:62.

159. Klauser P, Baker ST, Cropley VL, Bousman C, Fornito A, Cocchi L, et al. White matter disruptions in schizophrenia are spatially widespread and topologically converge on brain network hubs. Schizophr Bull. 2017;43:425-35.

160. van den Heuvel MP, Sporns O. Rich-club organization of the human connectome. J Neurosci. 2011;31:15775-86.

161. Fulcher $B D$, Fornito $A$. A transcriptional signature of hub connectivity in the mouse connectome. Proc Natl Acad Sci USA. 2016;113:1435-40.

162. Lutz PE, Tanti A, Gasecka A, Barnett-Burns S, Kim JJ, Zhou Y, et al. Association of a history of child abuse with impaired myelination in the anterior cingulate cortex: convergent epigenetic, transcriptional, and morphological evidence. Am J Psychiatry. 2017;174:1185-94.

163. Roussos P, Haroutunian V. Schizophrenia: susceptibility genes and oligodendroglial and myelin related abnormalities. Front Cell Neurosci. 2014;8:5.

164. Uranova NA, Vikhreva OV, Rakhmanova VI, Orlovskaya DD. Dystrophy of oligodendrocytes and adjacent microglia in prefrontal gray matter in schizophrenia. Front Psychiatry. 2020;11:204.

165. Bradl M, Lassmann H. Oligodendrocytes: biology and pathology. Acta Neuropathol. 2010;119:37-53.

166. Ravera $S$, Bartolucci $M$, Cuccarolo $P$, Litamè $E$, Illarcio $M$, Calzia $D$, et al. Oxidative stress in myelin sheath: The other face of the extramitochondrial oxidative phosphorylation ability. Free Radic Res. 2015;49:1156-64.

167. Monin A, Fournier M, Baumann PS, Cuenod M, Do OK Role of redox dysregulation in white matter anomalies associated with schizophrenia. In: Pletnikov MV, Waddington JL (eds). Handbook of Behavioral Neuroscience. Modeling the Psychopathological Dimensions of Schizophrenia: From Molecules to Behavior. Elsevier:New York, 2016, pp 481-500.

168. Monin A, Baumann PS, Griffa A, Xin L, Mekle R, Fournier M, et al. Glutathione deficit impairs myelin maturation: relevance for white matter integrity in schizophrenia patients. Mol Psychiatry. 2015;20:827-38.

169. Noble M, Smith J, Power J, Mayer-Pröschel M. Redox state as a central modulator of precursor cell function. Ann N. Y Acad Sci. 2003:991:251-71. 
170. Smith J, Ladi E, Mayer-Proschel M, Noble M. Redox state is a central modulator of the balance between self-renewal and differentiation in a dividing glial precursor cell. Proc Natl Acad Sci USA. 2000;97:10032-7.

171. Li Z, Dong T, Pröschel C, Noble M. Chemically diverse toxicants converge on Fyn and c-Cbl to disrupt precursor cell function. PLoS Biol. 2007;5:e35.

172. Maas DA, Vallès $A$, Martens GJM. Oxidative stress, prefrontal cortex hypomyelination and cognitive symptoms in schizophrenia. Transl Psychiatry. 2017;7:e1171.

173. Mauney SA, Pietersen CY, Sonntag KC, Woo TW. Differentiation of oligodendrocyte precursors is impaired in the prefrontal cortex in schizophrenia. Schizophr Res. 2015;169:374-80.

174. Corcoba A, Steullet P, Duarte JM, Van de Looij Y, Monin A, Cuenod M, et al. Glutathione deficit affects the integrity and function of the fimbria/fornix and anterior commissure in mice: relevance for schizophrenia. Int J Neuropsychopharmacol. 2015;19:pyv110.

175. Baumann PS, Griffa A, Fournier M, Golay P, Ferrari C, Alameda L, et al. Impaired fornix-hippocampus integrity is linked to peripheral glutathione peroxidase in early psychosis. Transl Psychiatry. 2016;6:e859.

176. Cai Z, Lin S, Pang Y, Rhodes PG. Brain injury induced by intracerebral injection of interleukin-1beta and tumor necrosis factor-alpha in the neonatal rat. Pediatr Res. 2004;56:377-84.

177. Chew L, Fusar-Poli P, Schmitz T. Oligodendroglial alterations and the role of microglia in white matter injury: relevance to schizophrenia. Dev Neurosci. 2013;35:102-29.

178. Fan LW, Pang Y, Lin S, Rhodes PG, Cai Z. Minocycline attenuates lipopolysaccharide-induced white matter injury in the neonatal rat brain. Neuroscience 2005;133:159-68.

179. Paintlia MK, Paintlia AS, Contreras MA, Singh I, Singh AK. Lipopolysaccharideinduced peroxisomal dysfunction exacerbates cerebral white matter injury: attenuation by N-acetyl cysteine. Exp Neurol. 2008;210:560-76.

180. Peferoen L, Kipp M, van der Valk P, van Noort JM, Amor S. Oligodendrocytemicroglia cross-talk in the central nervous system. Immunology 2014;141:302-13.

181. Cao N, Yao ZX. Oligodendrocyte N-methyl-D-aspartate receptor signaling: insights into its functions. Mol Neurobiol. 2013;47:845-56.

182. Cavaliere F, Urra O, Alberdi E, Matute C. Oligodendrocyte differentiation from adult multipotent stem cells is modulated by glutamate. Cell Death Dis. 2012;3:e268.

183. Li C, Xiao L, Liu X, Yang W, Shen W, Hu C, et al. A functional role of NMDA receptor in regulating the differentiation of oligodendrocyte precursor cells and remyelination. Glia 2013;61:732-49.

184. Rinholm JE, Vervaeke K, Tadross MR, Tkachuk AN, Kopek BG, Brown TA, et al. Movement and structure of mitochondria in oligodendrocytes and their myelin sheaths. Glia 2016;64:810-25.

185. Saab AS, Tzvetavona ID, Trevisiol A, Baltan S, Dibaj P, Kusch K, et al. Oligodendroglial NMDA receptors regulate glucose import and axonal energy metabolism. Neuron 2016;91:119-32.

186. Maas DA, Eijsink VD, Spoelder M, van Hulten JA, De Weerd P, Homberg JR, et al. Interneuron hypomyelination is associated with cognitive inflexibility in a rat model of schizophrenia. Nat Commun. 2020;11:2329.

187. Stedehouder J, Couey JJ, Brizee D, Hosseini B, Slotman JA, Dirven CMF, et al. Fast-spiking parvalbumin interneurons are frequently myelinated in the cerebral cortex of mice and humans. Cereb Cortex. 2017;27:5001-13.

188. Popovic D, Schmitt A, Kaurani L, Senner F, Papiol S, Malchow B, et al. Childhood trauma in schizophrenia: current findings and research perspectives. Front Neurosci. 2019;13:274.

189. Varese F, Smeets F, Drukker M, Lieverse R, Lataster T, Viechtbauer W, et al. Childhood adversities increase the risk of psychosis: a meta-analysis of patient-control, prospective- and cross-sectional cohort studies. Schizophr Bull. 2012;38:661-71.

190. Gomes FV, Zhu X, Grace AA. Stress during critical periods of development and risk for schizophrenia. Schizophr Res. 2019;213:107-13.

191. Soares AR, Gildawie KR, Honeycutt JA, Brenhouse HC. Region-specific effects of maternal separation on oxidative stress accumulation in parvalbumin neurons of male and female rats. Behav Brain Res. 2020;388:112658

192. Goodwill HL, Manzano-Nieves G, LaChance P, Teramoto S, Lin S, Lopez C, et al. Early life stress drives sex-selective impairment in reversal learning by affecting parvalbumin interneurons in orbitofrontal cortex of mice. Cell Rep. 2018;25: 2299-307.e2294.

193. Huang H, Gundapuneedi T, Rao U. White matter disruptions in adolescents exposed to childhood maltreatment and vulnerability to psychopathology. Neuropsychopharmacology 2012;37:2693-701.

194. Jackowski AP, Douglas-Palumberi H, Jackowski M, Win L, Schultz RT, Staib LW, et al. Corpus callosum in maltreated children with posttraumatic stress disorder: a diffusion tensor imaging study. Psychiatry Res. 2008;162:256-61.

195. Jensen SKG, Pangelinan M, Björnholm L, Klasnja A, Leemans A, Drakesmith M, et al. Associations between prenatal, childhood, and adolescent stress and variations in white-matter properties in young men. Neuroimage 2018;182:389-97.
196. Makinodan M, Rosen KM, Ito S, Corfas G. A critical period for social experience-dependent oligodendrocyte maturation and myelination. Science 2012;337:1357-60.

197. Alameda L, Golay P, Baumann PS, Ferrari C, Do KQ, Conus P. Age at the time of exposure to trauma modulates the psychopathological profile in patients with early psychosis. J Clin Psychiatry. 2016;77:e612-8.

198. Alameda L, Golay P, Baumann PS, Progin P, Mebdouhi N, Elowe J, et al. Mild depressive symptoms mediate the impact of childhood trauma on long-term functional outcome in early psychosis patients. Schizophr Bull. 2017;43:1027-35.

199. Alameda L, Fournier M, Khadimallah I, Griffa A, Cleusix M, Jenni R, et al. Redox dysregulation as a link between childhood trauma and psychopathological and neurocognitive profile in patients with early psychosis. Proc Natl Acad Sci USA. 2018;115:12495-500.

200. Willborn RJ, Hall CP, Fuller MA. Recycling N-acetylcysteine: a review of evidence for adjunctive therapy in schizophrenia. Ment Health Clin. 2019;9:116-23.

201. Yolland CO, Hanratty D, Neill E, Rossell SL, Berk M, Dean OM, et al. Meta-analysis of randomised controlled trials with $\mathrm{N}$-acetylcysteine in the treatment of schizophrenia. Aust N. Z J Psychiatry. 2020;54:453-66.

202. Zheng W, Zhang QE, Cai DB, Yang XH, Qiu Y, Ungvari GS, et al. N-acetylcysteine for major mental disorders: a systematic review and meta-analysis of randomized controlled trials. Acta Psychiatr Scand. 2018;137:391-400.

203. Berk M, Copolov D, Dean O, Lu K, Jeavons S, Schapkaitz I, et al. N-acetyl cysteine as a glutathione precursor for schizophrenia-a double-blind, randomized, placebo-controlled trial. Biol Psychiatry. 2008;64:361-8.

204. Farokhnia M, Azarkolah A, Adinehfar F, Khodaie-Ardakani MR, Hosseini SM, Yekehtaz $\mathrm{H}$, et al. $\mathrm{N}$-acetylcysteine as an adjunct to risperidone for treatment of negative symptoms in patients with chronic schizophrenia: a randomized, double-blind, placebo-controlled study. Clin Neuropharmacol. 2013;36:185-92.

205. Sepehrmanesh Z, Heidary M, Akasheh N, Akbari H, Heidary M. Therapeutic effect of adjunctive $\mathrm{N}$-acetyl cysteine (NAC) on symptoms of chronic schizophrenia: a double-blind, randomized clinical trial. Prog Neuropsychopharmacol Biol Psychiatry. 2018;82:289-96.

206. Rapado-Castro M, Dodd S, Bush Al, Malhi GS, Skvarc DR, On ZX, et al. Cognitive effects of adjunctive $\mathrm{N}$-acetyl cysteine in psychosis. Psychol Med. 2017;47:866-76.

207. Yolland COB, Phillipou A, Castle DJ, Neill E, Hughes ME, Galletly C, et al. Improvement of cognitive function in schizophrenia with $\mathrm{N}$-acetylcysteine: $\mathrm{A}$ theoretical review. Nutr Neurosci. 2020;23:139-48.

208. Breier A, Liffick E, Hummer TA, Vohs JL, Yang Z, Mehdiyoun NF, et al. Effects of 12-month, double-blind $\mathrm{N}$-acetyl cysteine on symptoms, cognition and brain morphology in early phase schizophrenia spectrum disorders. Schizophr Res. 2018;199:395-402.

209. Conus $P$, Seidman LJ, Fournier $M$, Xin $L$, Cleusix $M$, Baumann PS, et al. $\mathrm{N}$-acetylcysteine in a double-blind randomized placebo-controlled trial: toward biomarker-guided treatment in early psychosis. Schizophr Bull. 2018;44:317-27.

210. Lavoie S, Murray MM, Deppen P, Knyazeva MG, Berk M, Boulat O, et al. Glutathione precursor, $\mathrm{N}$-acetyl-cysteine, improves mismatch negativity in schizophrenia patients. Neuropsychopharmacology 2008;33:2187-99.

211. Carmeli C, Knyazeva MG, Cuénod M, Do KQ. Glutathione precursor N-acetylcysteine modulates EEG synchronization in schizophrenia patients: a doubleblind, randomized, placebo-controlled trial. PLoS ONE. 2012;7:e29341.

212. Klauser $P$, Xin L, Fournier M, Griffa $A$, Cleusix $M$, Jenni $R$, et al. $N$-acetylcysteine add-on treatment leads to an improvement of fornix white matter integrity in early psychosis: a double-blind randomized placebo-controlled trial. Transl Psychiatry. 2018;8:220.

213. Retsa $C$, Knebel JF, Geiser E, Ferrari $C$, Jenni $R$, Fournier $M$, et al. Treatment in early psychosis with $\mathrm{N}$-acetyl-cysteine for 6 months improves low-level auditory processing: pilot study. Schizophr Res. 2018;191:80-6.

214. Mullier E, Roine T, Griffa A, Xin L, Baumann PS, Klauser P, et al. N-acetyl-cysteine supplementation improves functional connectivity within the cingulate cortex in early psychosis: a pilot study. Int J Neuropsychopharmacol. 2019;22:478-87.

215. McQueen G, Lay A, Lally J, Gabay AS, Collier T, Lythgoe DJ, et al. Effect of single dose $\mathrm{N}$-acetylcysteine administration on resting state functional connectivity in schizophrenia. Psychopharmacology. 2020;237:443-51.

216. Çakici N, van Beveren NJM, Judge-Hundal G, Koola MM, Sommer IEC. An update on the efficacy of anti-inflammatory agents for patients with schizophrenia: a meta-analysis. Psychol Med. 2019;49:2307-19.

217. Wu Q, Huang J, Wu R. Drugs Based on NMDAR Hypofunction Hypothesis in Schizophrenia. Front Neurosci. 2021;15:641047.

218. Amminger GP, Nelson B, Markulev C, Yuen HP, Schäfer MR, Berger M, et al. The NEURAPRO biomarker analysis: long-chain omega-3 fatty acids improve 6-month and 12-month outcomes in youths at ultra-high risk for psychosis. Biol Psychiatry. 2020;87:243-52.

219. Amminger GP, Schäfer MR, Papageorgiou K, Klier CM, Cotton SM, Harrigan SM, et al. Long-chain omega-3 fatty acids for indicated prevention of psychotic 
disorders: a randomized, placebo-controlled trial. Arch Gen Psychiatry. 2010;67: 146-54.

220. Sedlak TW, Nucifora LG, Koga M, Shaffer LS, Higgs C, Tanaka T, et al. Sulforaphane augments glutathione and influences brain metabolites in human subjects: a clinical pilot study. Mol Neuropsychiatry. 2018;3:214-22.

221. Shiina A, Kanahara N, Sasaki T, Oda Y, Hashimoto T, Hasegawa T, et al. An open study of sulforaphane-rich broccoli sprout extract in patients with schizophrenia. Clin Psychopharmacol Neurosci. 2015;13:62-7.

222. Vomund S, Schäfer A, Parnham MJ, Brüne B, von Knethen A. Nrf2, the master regulator of anti-oxidative responses. Int J Mol Sci. 2017;18:2772.

223. Chang CH, Lane HY, Tseng PT, Chen SJ, Liu CY, Lin CH. Effect of N-methyl-Daspartate-receptor-enhancing agents on cognition in patients with schizophrenia: a systematic review and meta-analysis of double-blind randomised controlled trials. J Psychopharmacol. 2019;33:436-48.

224. Dunayevich E, Buchanan RW, Chen CY, Yang J, Nilsen J, Dietrich JM, et al. Efficacy and safety of the glycine transporter type-1 inhibitor AMG 747 for the treatment of negative symptoms associated with schizophrenia. Schizophr Res. 2017;182:90-7

225. Kantrowitz JT, Woods SW, Petkova E, Cornblatt B, Corcoran CM, Chen H, et al $\mathrm{D}$-serine for the treatment of negative symptoms in individuals at clinical high risk of schizophrenia: a pilot, double-blind, placebo-controlled, randomised parallel group mechanistic proof-of-concept trial. Lancet Psychiatry. 2015;2:403-12.

226. Lane HY, Lin CH, Green MF, Hellemann G, Huang CC, Chen PW, et al. Add-on treatment of benzoate for schizophrenia: a randomized, double-blind, placebocontrolled trial of D-amino acid oxidase inhibitor. JAMA Psychiatry. 2013;70: 1267-75.

227. Lane HY, Liu YC, Huang CL, Chang YC, Liau CH, Perng CH, et al. Sarcosine (N-methylglycine) treatment for acute schizophrenia: a randomized, doubleblind study. Biol Psychiatry. 2008;63:9-12.

228. Lin $\mathrm{CH}$, Lin $\mathrm{CH}$, Chang YC, Huang YJ, Chen PW, Yang HT, et al. Sodium benzoate, a D-amino acid oxidase inhibitor, added to clozapine for the treatment of schizophrenia: a randomized, double-blind, placebo-controlled trial. Biol Psychiatry. 2018;84:422-32.

229. Umbricht $D$, Alberati D, Martin-Facklam M, Borroni E, Youssef EA, Ostland $M$, et al. Effect of bitopertin, a glycine reuptake inhibitor, on negative symptoms of schizophrenia: a randomized, double-blind, proof-of-concept study. JAMA Psychiatry. 2014;71:637-46.

\section{ACKNOWLEDGEMENTS}

We thank Dr. Byron Bitanihirwe for his excellent assistance with the preparation of the manuscript, Morgane Baumgartner, Adeline Cottier and Gloria Reuteler for their helpful technical assistance, and Dr Fulvio Magara and the technical staff of the "Centre d'Etudes du Comportement" (Center for Psychiatric Neuroscience, CHUV) for their support in animal facilities. We also thank Martine Cleusix, Raoul Jenny, Dr Alessandra Solida and all the staff of the Minkowski Section for the recruitment and clinical evaluation of patients. Last but not least, we are grateful to all patients for their precious participation. Swiss National Science Foundation (\# 31-116689 to KQD and \# 310030_135736/1 to KQD and PS), National Center of Competence in Research
(NCCR) "SYNAPSY - The Synaptic Bases of Mental Diseases" from the Swiss National Science Foundation ( $\mathrm{n}^{\circ}$ 51AU40_185897 to KQD \&PC), Avina Foundation, DammEtienne Foundation, and Alamaya Foundation.

\section{AUTHOR CONTRIBUTIONS}

MC: conceptualization, writing original manuscript. PS: writing original manuscript. JHC: writing/review/editing. DD: writing/review/editing. IK: writing/review/editing. PK writing/review/editing. PC: writing/review/editing, funding acquisition. KQD: conceptualization, writing/review/editing, funding acquisition.

\section{FUNDING}

Open access funding provided by University of Lausanne.

\section{COMPETING INTERESTS}

A European Patent application has been filed (EP19218841.5) in relation to the development of diagnostic test concerning mitochondrial impairments. KQD and DD have received grant support not related to this review from Boehringer-Ingelheim. The remaining authors declared no competing interests.

\section{ADDITIONAL INFORMATION}

Correspondence and requests for materials should be addressed to Kim Q. Do.

Reprints and permission information is available at http://www.nature.com/ reprints

Publisher's note Springer Nature remains neutral with regard to jurisdictional claims in published maps and institutional affiliations.

(i) Open Access This article is licensed under a Creative Commons Attribution 4.0 International License, which permits use, sharing, adaptation, distribution and reproduction in any medium or format, as long as you give appropriate credit to the original author(s) and the source, provide a link to the Creative Commons license, and indicate if changes were made. The images or other third party material in this article are included in the article's Creative Commons license, unless indicated otherwise in a credit line to the material. If material is not included in the article's Creative Commons license and your intended use is not permitted by statutory regulation or exceeds the permitted use, you will need to obtain permission directly from the copyright holder. To view a copy of this license, visit http://creativecommons. org/licenses/by/4.0/.

C The Author(s) 2021 